\title{
LWRS II\&C Industry and Regulatory Engagement Activities for FY 2011
}

Kenneth D. Thomas

September 2011

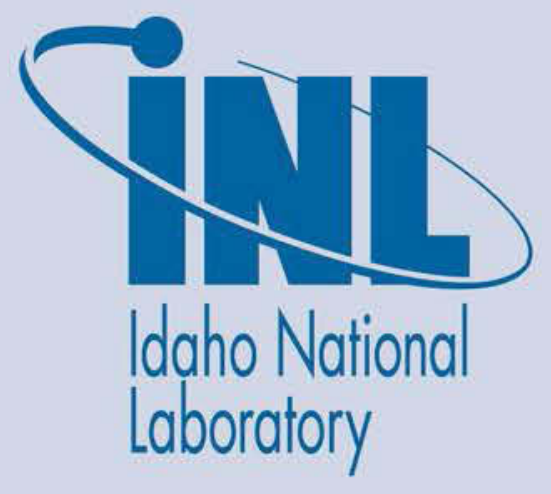

The INL is a U.S. Department of Energy National Laboratory operated by Battelle Energy Alliance 


\section{DISCLAIMER}

This information was prepared as an account of work sponsored by an agency of the U.S. Government. Neither the U.S. Government nor any agency thereof, nor any of their employees, makes any warranty, expressed or implied, or assumes any legal liability or responsibility for the accuracy, completeness, or usefulness, of any information, apparatus, product, or process disclosed, or represents that its use would not infringe privately owned rights. References herein to any specific commercial product, process, or service by trade name, trade mark, manufacturer, or otherwise, does not necessarily constitute or imply its endorsement, recommendation, or favoring by the U.S. Government or any agency thereof. The views and opinions of authors expressed herein do not necessarily state or reflect those of the U.S. Government or any agency thereof. 


\title{
LWRS II\&C Industry and Regulatory Engagement Activities for FY 2011
}

\author{
Kenneth D. Thomas
}

September 2011

Idaho National Laboratory Idaho Falls, Idaho 83415

http://www.inl.gov

Prepared for the

U.S. Department of Energy

Office of Nuclear Energy

Under DOE Idaho Operations Office

Contract DE-AC07-05ID14517 



\section{ACKNOWLEDGMENTS}

The author would like acknowledge the support of Idaho National Laboratory and the Electric Power Research Institute in sponsoring this new working group. The author would also like to thank the many individuals and their organizations that have contributed to the formation of this working group. 


\section{CONTENTS}

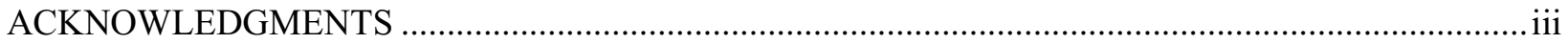

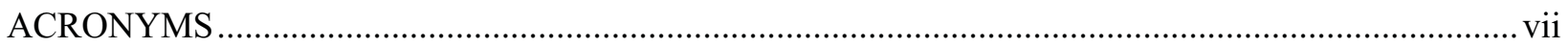

1. INDUSTRIAL AND REGULATORY ENGAGEMENT FY 2011 ACCOMPLISHMENTS.......... 9

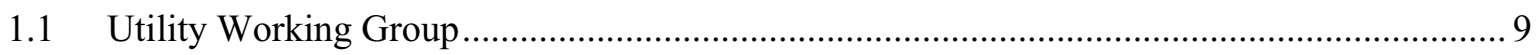

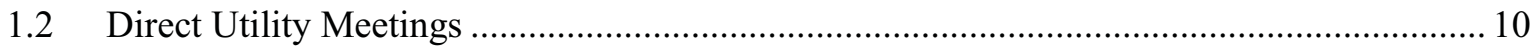

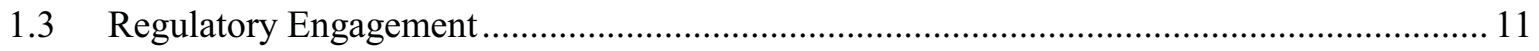

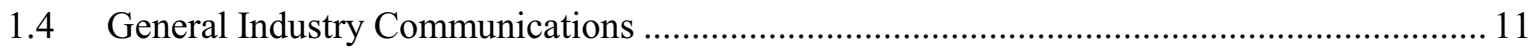

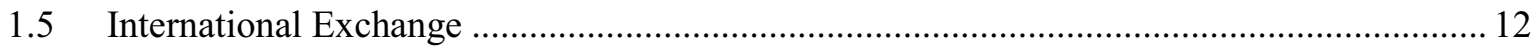

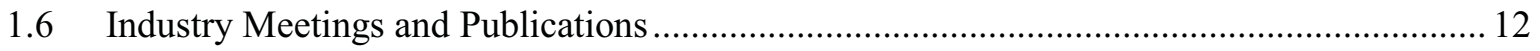

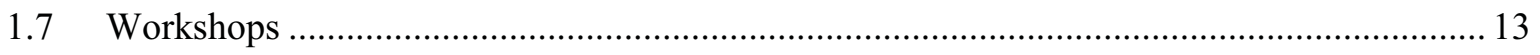

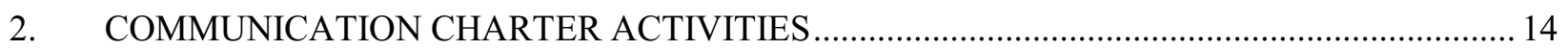

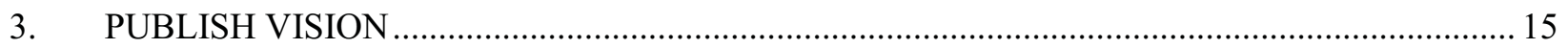

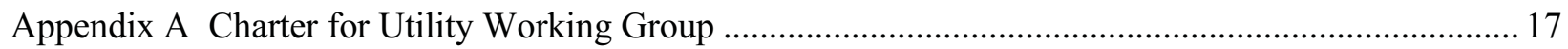

Appendix B DOE Life Extension Workshop Transforming Plant Operations with Digital

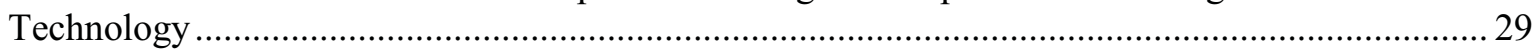

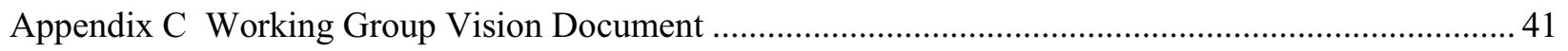

Appendix D DOE Bi Lateral Meeting Presentation for BEWG …..................................................... 53

Appendix E ANS UWC Advanced II\&C Working Group ............................................................. 73

\section{FIGURES}

Figure 1. Practical Limit of the Current Human Performance Paradigm.................................................2 24

Figure 2. Performance Improvement of the New Paradigm. ...................................................................25 


\section{ACRONYMS}

ANS American Nuclear Society

DOE Department of Energy

DOE-NE Department of Energy Office of Nuclear Energy

EPRI Electric Power Research Institute

FY Fiscal Year

HMI Human-Machine Interface

HRP Halden Reactor Project

II\&C Instrumentation, Information, and Controls

INL Idaho National Laboratory

INPO Institute of Nuclear Power Operations

LTO Long-Term Operations

LWR Light-Water Reactor

LWRS Light Water Reactor Sustainability

LWRSP Light Water Reactor Sustainability Program

MTO Man-Technology Organization

NEI Nuclear Energy Institute

NPIC \& HMIT Nuclear Plant Instrumentation, Control, and Human-Machine Interface Technologies

NPP Nuclear Power Plant

NRC Nuclear Regulatory Commission

ORNL Oak Ridge National Laboratory

PNNL Pacific Northwest National Laboratory

PWROG Pressurized Water Reactor Owners Group

R\&D Research and Development

SCE Southern California Edison

UWC Utility Working Conference

VR Virtual Reality 


\section{LWRS II\&C Industry and Regulatory Engagement Activities for FY 2011}

\section{INDUSTRIAL AND REGULATORY ENGAGEMENT FY 2011 ACCOMPLISHMENTS}

To ensure broad industry support and coordination for the Advanced Instrumentation, Information, and Controls (II\&C) Systems Technologies research pathway, an engagement process will be continually pursued with nuclear asset owners, vendors, and suppliers, Nuclear Regulatory Commission (NRC), and the major industry support organizations of Electric Power Research Institute (EPRI), Institute of Nuclear Power Operations (INPO), and Nuclear Energy Institute (NEI). Nuclear asset owner engagement is a necessary and enabling activity to obtain data and accurate characterization of long-term operational challenges, assess the suitability of proposed research for addressing long-term needs, and gain access to data and representative infrastructure and expertise needed to ensure success of the proposed research and development (R\&D) activities. Engagement with vendors and suppliers will ensure that vendor expectations and needs can be translated into requirements that can be met through technology commercialization.

The outcome of these activities will be an in-depth understanding of the II\&C research program throughout the commercial nuclear industry, broad participation by the asset owners and their technology suppliers, and coordination of effort among the major nuclear industry support organizations in enabling a wide-scale modernization of legacy II\&C systems. This will ensure a unified approach within the commercial nuclear industry in addressing the Light Water Reactor Sustainability (LWRS) concern with respect to legacy II\&C systems.

The following describes the accomplishments in Fiscal Year (FY) 2011 to these ends.

\subsection{Utility Working Group}

The LWRS Advanced II\&C Working Group continues to expand its engagement with leading U.S. nuclear utilities and associated support organizations. This involves regular meetings and conference calls to discuss and provide input on the LWRS II\&C pilot projects and related technical topics. These opportunities serve as an ongoing forum to get broad industry input from II\&C experts and innovation leaders on the direction and objectives of related research projects.

The first meeting of the Working Group for FY12 was held in Las Vegas, Nevada on November 8, 2010, in conjunction with the 2010 ANS Winter Meeting. In attendance were representatives of Exelon, Wolf Creek Nuclear Operating Company, Pacific Gas and Electric, Duke Energy, NRC, the Department of Energy (DOE), Idaho National Laboratory (INL), Oak Ridge National Laboratory (ORNL), Pacific Northwest National Laboratory (PNNL), and Halden. Presentations were made on the Outage Safety and Efficiency pilot project, the Alarm Management pilot project, and the Human Performance for Nuclear Power Plant (NPP) Field Workers pilot project.

The Working Group held its second formal meeting in Washington DC on February 24, in conjunction with the 2011 DOE Life Extension Workshop. The meeting was attended by Duke Energy, Exelon, Entergy, Electric Power Research Institute (EPRI), and INL. This meeting resulted in the identification of a number of II\&C research topics of interest to working group member companies, which were included for consideration in the long-range plan of the research program. In addition, the Working Group conducted a session in the Life Extension Workshop with presentations by INL, Exelon, Entergy, and Duke Energy. This event served as a significant communication opportunity to a broad cross section of nuclear utilities, national laboratories, and government agencies on the activities of the Working Group. 
The third meeting of the Working Group was a major workshop held in Idaho Falls, Idaho on September 13-15. The purpose of the meeting was to:

- Obtain Utility Working Group input on the long-term vision for II\&C

- Have opportunity for interaction with INL researchers working on the pilot projects

- Conduct demonstrations of the pilot project technologies

- Review of the 2012 research plan

- Conduct demonstrations of Halden Reactor Project (Norway) technologies

- Conduct a tour and demonstration of the Human System Simulation Laboratory (reconfigurable simulator and Virtual Reality (VR)Cave

- Provide an opportunity for networking and collaboration among the working group members.

The meeting was attended by the following utilities: Constellation Energy, Exelon, Duke Energy, Southern Nuclear, South Texas Project, Arizona Public Service, and Southern California Edison. In addition, representatives of INL, EPRI, and DOE-NE attended.

The Working Group conducts a monthly phone call in which the utility sponsors of the pilot projects update the other members on the status and progress of their respective projects. Specific pilot projects that have been discussed are the Exelon Pilot Project on Outage Management, the Duke Pilot Project on Improving Human Performance for Plant Configuration Management, and the potential Southern California Edison (SCE) Pilot Project on Advanced Control Room Alarm Systems. This provides immediate and direct communications on the results of the research and the potential involvement of the other member companies.

The membership in the Working Group currently includes Constellation Energy, Southern California Edison South Texas Project, Exelon, Entergy, Duke Energy, Pacific Gas and Electric, Arizona Public Service, Southern Company, Progress Energy, EPRI, and INL.

\subsection{Direct Utility Meetings}

A meeting at Palo Verde Nuclear Generating Station (Arizona Public Service) on July 21, 2011, at the request of station managers to discuss opportunities of the research program. The station shared their plans for comprehensive performance improvement, which includes the use of technology applied to many aspects of their current work methods, in addition to the upgrade of II\&C systems. Of particular note was the Palo Verde concept of the "Worker of the Future." Presentations of the Advanced II\&C research pathway work were made to several station groups, including Radiation Protection, Engineering, Operations, Information Technology, and station senior leadership.

Numerous common interests were identified with the Advanced II\&C research pathway, which will be explored in future meetings. As a result of the meeting, Palo Verde joined the Utility Working Group with two designated members: the Site Programs Director, who will represent interests in the areas of station process and human performance improvement; and the lead for II\&C upgrades, who will participate in opportunities in the development of advanced II\&C technologies. The station also expressed their intent to send three representatives to the September Utility Working Group meeting, namely, the Site Program Director, Lead Engineer for II\&C upgrade strategy, and the Assistant Plant Manager.

A meeting was held at Progress Energy General Office, August 10, 2011, with the Corporate Functional Areas Manager responsible for plant procedures across the four station nuclear fleet. A presentation was made on the research program in general, as well as the proposed FY 2012 project on computer-based procedures. Progress expressed strong interest in participating in the computer-based procedure project, both in the areas of control room procedures as well as procedures for in-plant activities. This project directly relates to an internal initiative to move to a paperless process for 
procedures. Progress requested an additional meeting at their location to provide a briefing for their management.

\subsection{Regulatory Engagement}

The NRC participated in the Working Group meeting held in Las Vegas, Nevada on November 8, 2010, and stated that continuing involvement would be beneficial to the NRC. There was specific discussion on the need for the NRC to have human factors experts participate as the pilot project on alarm management progresses. It was agreed that the NRC would be invited to participate in Working Group meetings and workshops when advantageous to keep the NRC advised of the consideration of new technologies that could possibly be implemented in the LWR fleet.

\subsection{General Industry Communications}

A session was conducted by the Working Group at the DOE 2011 Second Workshop on U.S. Nuclear Power Plant Life Extension and Development, February 22-24, 2011, held in Washington, DC. This meeting was attended by representatives of utilities, suppliers, and industry support groups involved in life extension for the LWR fleet. The following presentations were made.

1. Overview of the Advanced II\&C Systems Technologies Research Program (INL)

2. Transforming Plant Operations with Digital Technology (INL)

3. New Strategies and Technologies for Outage Management (Exelon)

4. Advanced I\&C and Plant Productivity Initiatives (EPRI)

5. Digital Technology to Improve Plant Status Control (Duke)

6. Online Monitoring Technologies for Equipment Reliability (Entergy).

As a direct result of contacts made while participating in this DOE workshop on nuclear plant life extension, Constellation Energy joined the Working Group.

A presentation was made to the Procedure Professionals Association, Virginia Beach, Virginia, June 16, 2011, on the plans of the research program for computer-based procedures. Over 40 utility and supplier representatives attended the meeting. As a result of this meeting, two additional utilities joined the Working Group: Progress Energy and Arizona Public Service. Both have since hosted meetings with a Working Group representative at their locations and sent representatives to the September Working Group meeting in Idaho Falls.

The Working Group sponsored a session at the American Nuclear Society (ANS) Utility Working Conference (UWC) Hollywood, Florida, August 15-17, 2011, entitled "Advanced I\&C and Information Technology Needs for Long Term Operations.” The following presentations were made in this session:

1. Advanced II\&C Working Group - a DOE/EPRI/Utility Collaboration (INL)

2. Addressing Human Performance with Technology (Duke)

3. Reducing Error / Increasing Efficiency: New Models for Nuclear Plant Outages (Exelon)

4. SONGS Advanced Alarm Systems (Southern California Edison).

The UWC is attended by a large number of utility executives and managers, and is considered to be one of the foremost industry meetings for exchange of new developments and innovative ideas for nuclear operators. This session provided the opportunity to describe the overall purpose and charter of the Working Group, the future vision for II\&C modernization, and the achievements of the early pilot projects. As a result of contacts made in this meeting, the fleet leads for future I\&C upgrade strategy for both Duke Energy and Progress Energy were added to the Working Group. (While both of these companies were already part of the Working Group, their interests and representation up to this point 
were in the plant work process applications as opposed to I\&C upgrades.) Also of note, several leading nuclear I\&C suppliers expressed interest in learning more about the research program and whether there were opportunities for their participation. A strategy for communicating the future vision and research objectives to the supplier community will be addressed during FY 2012

A presentation was made to the Pressurized Water Reactor Owners Group (PWROG) in a joint meeting with the DOE, held in Rockville, Maryland, on August 23, 2011, entitled "LWRSP Advanced Instrumentation, Information, and Control Systems Technologies R\&D Program.” This group represents the majority of plant operators for issue resolutions and innovations undertaken by the reactor system suppliers. The PWROG expressed interest in the research program and initiated an action item to inquire about having a representative of the PWROG I\&C Working Group on the Light Water Reactor Sustainability Program (LWRSP) Adv II\&C Working Group. This will be considered as part of the strategy to engage nuclear industry supplier community during FY 2012.

\subsection{International Exchange}

The INL lead for the Working Group attended the Halden Reactor Project (HRP) Programme Meeting in Budapest, Hungary, on May 12-13, 2011. As part of the meeting, the Proposal for the 3-year period 2012-2014 for the Man-Technology-Organisation (MTO) Programme was presented. The MTO Programme Proposal consists of research projects in the areas of control room modernization, new control room concepts, development of advanced outage control centers, technology for field operators, new NPP operational concepts, technology for knowledge management, and methodologies for assuring highintegrity software. Presentations were made for each of these areas including wearable technology/ubiquitous computing (heads-up, hands-free displays), hand-held devices that can depict abstract information, a "touch-table" interactive desktop for collaborative problem solving, control room design and layout software, HRA modeling developments, integrated system validation techniques, and online condition monitoring. The information gained in this meeting has been used to formulate aspects of the future vision for the Working Group and the formulation of proposed pilot projects that will be opportunities for interested Working Group member utilities to host. The meeting also provided the opportunity to engage representatives from some of the leading utilities in Europe, regarding plans they have to modernize their II\&C systems. This exchange proved useful in validating many of the assumptions and proposed developments that are of interest to the Working Group.

A presentation was made at the DOE Bilateral Energy Working Group Meeting (with representatives of Argentina), in Albuquerque, New Mexico, on August 3, 2011, entitled, "Replacement Strategy for Aging Instrumentation and Control." The result of the meeting was to set up an exchange of information on the methodologies used to facilitate the modernization of control and information systems used at NPPs. This ongoing exchange will likewise provide a valuable source of technical information and concept validation for the future vision and proposed technology developments of interest to the Working Group.

\subsection{Industry Meetings and Publications}

A paper was presented at the Seventh American Nuclear Society International Topical Meeting on Nuclear Plant Instrumentation, Control, and Human-Machine Interface Technologies (NPIC \& HMIT) 2010, Las Vegas, Nevada, November 7-11, 2010, entitled "Development of a New Working Group on Advanced Instrumentation, Control, and Information System Technology for the LWR Sustainability Program." This meeting is widely-attended by I\&C professionals in the nuclear industry. The paper was both published in the proceeding of the meeting and presented in one of the technical sessions. This provided an opportunity to publish the objectives of the research program and the purpose and charter of the Working Group. The presentation generated substantial interest in the research program with utilities, suppliers, and research organizations, as indicated by follow-up contacts for additional information. 


\subsection{Workshops}

To address the possibilities for alarm system improvement in conjunction with control room upgrades, INL hosted a workshop in Idaho Falls, Idaho, June 14-16, 2001, on "Alarm Design for Control Room Upgrades." The workshop consisted of presentations by Halden Reactor Project experts in design of digital control rooms, in addition to INL experts on alarm system management and regulatory considerations in pursuing these types of systems. The workshop featured the following topics:

- Opportunities and trade-offs with digital control rooms

- Lessons learned from existing alarm system upgrades

- Discussion of effective design processes

- A review of the process and lessons learned in the recent digital alarm upgrade at INL's Advanced Test Reactor control room

- A tour of INL's Human System Simulation Laboratory, which can be configured to run control room simulator studies for testing design upgrades

- A hands-on exercise to redesign an analog annunciator panel, with the workshop participants divided into small groups for direct guidance and instruction from the Halden and INL experts.

The workshop was attended by representatives of Southern California Edison's San Onofre Nuclear Generating Station, in addition to participants from other sectors of the nuclear power industry. The workshop also served as a valuable opportunity to explore alarm modernization ideas generated during the workshop, and to validate these ideas with representatives of the Working Group. 


\section{COMMUNICATION CHARTER ACTIVITIES}

The activities and charter of the Advanced II\&C Systems Technologies Utility Working Group were communicated to the broader nuclear power industry by the publication of an ANS paper entitled "Development of a New Working Group on Advanced Instrumentation, Control, and Information System Technology for the LWR Sustainability Program." The paper was presented at the Seventh American Nuclear Society International Topical Meeting on NPIC \& HMIT 2010, Las Vegas, Nevada, November 7-11, 2010. It was presented in session General I\&C - III on November 11, 2010 and published as part of the proceedings of the meeting.

The following are other instances where the activities and charter of the Working Group were communicated to nuclear power industry groups.

- A presentation was made at the DOE 2011 Second Workshop on U.S. Nuclear Power Plant Life Extension and Development, February 22-24, 2011, held in Washington, DC. This meeting was attended by representatives of utilities, suppliers, and industry support groups involved in life extension for the LWR fleet.

- A presentation was made to the Procedure Professionals Association, Virginia Beach, Virginia, June 16, 2011, on the plans of the research program for computer-based procedures. Over 40 utility and supplier representatives attended the meeting.

- A presentation was made at the ANS UWC Hollywood, Florida, August 15-17, 2011. The UWC is attended by a large number of utility executives and managers, and is considered to be one of the foremost industry meetings for exchange of new developments and innovative ideas for the nuclear operators. This session provided the opportunity to describe the overall purpose and charter of the Working Group, the future vision for II\&C modernization, and the achievements of the early pilot projects.

- A presentation was made to the PWROG in a joint meeting with DOE, held in Rockville, Maryland, on August 23, 2011, entitled "LWRSP Advanced Instrumentation, Information, and Control Systems Technologies R\&D Program." This group represents the majority of plant operators for issue resolutions and innovations undertaken by the reactor system suppliers. 


\section{PUBLISH VISION}

The Vision Document of the Advanced Instrumentation, Information, and Control (II\&C) Systems Technologies Utility Working Group was published as an ANS paper entitled "Development of a New Working Group on Advanced Instrumentation, Control, and Information System Technology for the LWR Sustainability Program," as part of the proceedings of the Seventh ANS International Topical Meeting on NPIC \& HMIT 2010, Las Vegas, Nevada, November 7-11, 2010. 
Appendix A

Charter for Utility Working Group 


\title{
Appendix A \\ Charter for Utility Working Group
}

\author{
Development of a New Working Group on Advanced Instrumentation, Control and \\ Information System Technology for the LWR Sustainability Program
}

\begin{abstract}
This paper provides an overview of the development of a new working group on Advanced Instrumentation, Control and Information Systems Technology, as part of the Light-Water Reactor (LWR) Sustainability Program, approved by Congress in the 2010 Energy Bill. The LWR Sustainability Program is a research and development (R\&D) program sponsored by the Department of Energy (DOE) and performed in close collaboration with industry R\&D programs to provide the technical foundations for licensing and managing the long-term, safe, and economical operation of current nuclear power plants. DOE's program focus is on longer-term and higher-risk/reward research that contributes to the national policy objectives of energy security and environmental security.

The domestic nuclear power industry has positioned itself to continue as a primary source of energy in the future. This is in large part due to the impressive safety and production record the industry has achieved. To sustain this success, the industry will need transformative change to overcome looming future challenges: replacing outdated plant technology in critical plant systems, managing plant assets for longterm operation (life extension), overcoming potential shortages of skilled labor, and reducing susceptibility to human error. Digital technology can play a significant role in this transformation.

The Working Group on Advanced Instrumentation, Control and Information System Technology for the LWR Sustainability Program will assist this transformation by sponsoring projects that will demonstrate the full potential of digital technology. Further, it will advocate for research to define a future operating/support model that exploits digital capabilities and defines the logical pathway to attain it. In this way, it will undergird the national effort to ensure the sustainability of the LWR fleet as part of the long-term national energy supply.
\end{abstract}

\section{INTRODUCTION}

The purpose of this paper is to provide an overview of the development of a new working group on Advanced Instrumentation, Control and Information Systems Technology, as part of the LWR Sustainability Program, approved by Congress in the 2010 Energy Bill. The LWR Sustainability Program is an $\mathrm{R} \& \mathrm{D}$ program sponsored by DOE and performed in close collaboration with industry $\mathrm{R} \& \mathrm{D}$ and improvement programs to provide the technical foundations for licensing and managing the long-term, safe and economical operation of current nuclear power plants. DOE's program focus is on longer-term and higher-risk/reward research that contributes to the National Policy objectives of energy security and environmental security.[1]

This paper describes the origin, purpose, and current progress of the working group. It discusses the need for the working group in view of the current status of digital implementation for U.S. nuclear plants and the barriers to wide-scale implementation. Finally, the paper presents solutions to overcome these barriers.

\subsection{Origin of the Working Group}

A workshop entitled "Instrumentation and Control, Human System Interface, and Information Technology Requirements for Nuclear Power Plant Long-term Operation" was held in Columbus, Ohio, in March 2009.[2] A common theme in the workshop was the recognition that digital technology is the 
foremost enabler of nuclear plant performance improvement and modernization to support long-term operations. However, it was also recognized that current nuclear power plant operators have taken a limited and piecemeal approach to digital implementation for a variety of reasons. As a result, the U.S. commercial nuclear power fleet has not obtained the full benefit of digital technologies as have been realized in other industry sectors, including even the fossil and hydro commercial power fleets.

One of the primary conclusions of the workshop report was that a robust research program is needed to develop a path forward for wide-scale digital modernization for U.S. nuclear power plants. To address this current limited approach, the research program needs to define a path forward to a future plant operating/support model based on the integrated use of these technologies. Further, it must demonstrate the cost-effectiveness of near-term technologies that in turn can serve as logical stepping stones to this future plant operating/support model.

To pursue this research program, three additional meetings have been held involving U.S. utilities, the U.S. DOE), INL, Electric Power Research Institute (EPRI), and participating industry consultants/suppliers. These meetings have resulted in the formation of the Advanced Instrumentation, Control, and Information Technology for the LWR Sustainability Program Working Group as the means of establishing this research program.

\subsection{Purpose of the Working Group}

The purpose of the Working Group is to define and sponsor research projects that will collectively enable significant plant performance gains and minimize operating costs as part of the larger national effort to ensure long-term sustainability of the LWR fleet. Specifically, the Working Group will:

- Develop agreements with host utilities to demonstrate near-term beneficial digital applications that improve performance at lower cost.

- Obtain funding for these projects through a variety of means such as government grants, industry shared research funding, and pay-for-performance financial business models.

- Coordinate project development among research organizations associated with the U.S commercial nuclear industry, to the degree practical, to minimize duplication of effort.

- Sponsor research on a long-term vision of the nuclear power plant operating/support model based on substantial digital technology integration, and sponsor research on methodologies to identify the costbeneficial opportunities to transition various plant support functions to a digital technology infrastructure.

- Communicate the work of this research program to utility and support industry decision makers to build a collective vision for a transformed plant operating/support model based on digital technology.

- Coordinate with major nuclear industry support organizations (e.g., NEI, EPRI, and INPO), to the degree practical, in the pursuit of complementary digital technology developments such as appropriate regulatory requirements, technology applications and guidance, and standards of excellence in digital implementation.

\subsection{Progress of the Working Group}

Currently, one agreement with a host utility has been completed to pursue an advanced control room alarm system as part of their long-term control room modernization strategy. This research project will be conducted by INL, building on their experience in advanced digital I\&C systems, highly-integrated control rooms, and human factors research. This project is representative of research projects that directly improve the plant systems and component infrastructure, as well as the operator interface.

A second agreement is currently being pursued in the area of human performance improvement, specifically in the area of plant status control and operational configuration management. This agreement, 
if concluded, will apply digital technology to plant support activities such as safety tagging, conducting operational line-ups (valves, switches, etc.), verifying safety system readiness, etc. This project is representative of research projects that improve human performance in tedious day-to-day operational support activities that are susceptible to active and latent human error.

The Working Group is also developing a communication strategy to inform the utilities and support organizations of this research program and the opportunities to become involved. The intent is to build confidence among key industry decision makers that wide-scale digital implementation is indeed an enabler of significant business improvement and that U.S. nuclear plants can be substantially transformed, similar to other high-tech industry sectors such as aviation, manufacturing, and communications.

\section{WHY THIS WORKING GROUP IS NEEDED}

Digital technology has been a driving force of general industrial performance improvement for over 2 decades, leading to unprecedented levels of productivity and quality improvement. Industry after industry has made the "digital transformation" as a matter of economic survival, such that their operations and support functions are now largely integrated with digital technology. Unfortunately, during this time of rapid digital proliferation, there were no new domestic nuclear plants under design, so the nuclear power industry generally missed out on this transformation, other than for some point applications to address reliability issues. Also, during this time, the nuclear power industry placed its focus on improving basic nuclear safety and establishing reliable operations, with these efforts consuming the majority of investment resources.

\subsection{Barriers to Wide-Scale Digital Implementation}

Nuclear plant operators are saddled with significant barriers to making the large investments needed to redefine the operating/support model and to modernize the plant assets. The plants were designed with I\&C and Human-Machine Interface Technology (HMI) rooted in the 1970s. The limits of technology at the time necessitated large plant staffs with specialized skills to accomplish the vast number of work activities needed to support production and to ensure nuclear safety. Some of the more significant barriers are as follows.

There is enormous investment in the work process infrastructure (training, procedures, task qualifications, etc.) to support the labor-centric approach to operating the plant and it is very expensive to change these documents, revalidate them, and to deal with the human factors effects of such changes.

The NRC-approved safety analysis of these plants credits the current design of the plant systems. The pursuit of licensing changes for digital technology exposes the company to substantial risks in new regulatory requirements, cost increases, and schedule delays.

The cost competitiveness of nuclear plants is founded on the idea that a large initial capital investment results in lower ongoing operating costs. The fixed plant assets are typically depreciated over decades, in contrast to the shorter depreciation times for technology in other industry sectors. This limits the ability of the nuclear industry to continually to make large capital upgrades for new technology.

The current performance of the U.S. fleet is at an all time high, thus narrowing the performance improvement opportunity to achieve higher capacity factors, fewer plant transients, and fewer safety challenges.[3]

Therefore, it is not surprising that the industry has made little progress in modernizing the plants and has resorted to a like-for-like replacement strategy for digital upgrades when necessitated by reliability and obsolescence issues. While this approach has been the path of least regulatory risk and impact to the operating infrastructure (training, procedures, etc.), it has served to reinforce the old operating/support model rather than leading to a transformed model that evolves with ever-improving technology. 


\subsection{Opportunity for Collective Industry Improvement}

The U.S. nuclear power industry is somewhat unique in how similar each nuclear utility conducts its operations. In fact, the success of the industry as a whole is largely due to the open, sharing nature of the industry wherein new beneficial practices are rapidly adopted throughout the operating fleets. In turn, these operating practices become somewhat of de facto expectations by the industry and the regulator as a whole. This has created significant inertia in the present operating/support model, with limited divergence by individual nuclear plants. This has constrained digital technology to a role of supporting the present operating/support model rather than transforming it.

To achieve the full potential of digital technology to improve performance, the industry must work together to collectively transform the operating/support model, using these same practices of rapidly adopting proven innovations across the industry. This new working group will foster this digital transformation in a manner that reduces technical and financial risk, while providing a pathway to this new operating/support model. It will also cooperate with the major industry support organizations to facilitate all aspects of the transformation.

\section{CHALLENGES FOR NUCLEAR ENERGY SUSTAINABILITY}

Today, nuclear energy is one of the lowest-cost energy sources available and is often touted as the only large-scale source of carbon-free energy. Due to its excellent safety and operating record, the nuclear industry seems poised for what was once a very unlikely renaissance. Opponents of nuclear energy have for the most part lost the debate on safety and environmental issues. They now tend to focus on the high capital investment and long-term financial risk for new nuclear plants. They are quick to point out that other forms of energy production, particularly renewable, might render the plants obsolete long before the capital investments are recovered.

Indeed, over the life of the proposed new plants and the extended life of current plants (perhaps up to 80 years), nuclear energy will have to compete with a number of emerging clean energy sources that are technology, rather than labor, intensive. As stated previously, the current operating/support model of nuclear plants is based on a large workforce working with somewhat dated technologies. And so, the costcompetitiveness of nuclear power going forward could well depend on the cost-performance curves of technology compared to human labor. Historically, it is a fact that technology costs are falling whereas labor costs are ever-increasing.

Ironically, the operating/support model that achieved the high performance of the present LWR fleet might not have the same success going forward in the coming business environment. However, digital technology is a proven enabler of business transformation that can address many of the inevitable challenges of the future. It promotes sustainability of the LWR fleet in four key areas:

- Modernizing instrumentation, information, and human-machine interface (HMI) systems

- Managing plant assets to support long-term operations (LTO)

- Reducing dependence on a large highly-skilled workforce

- Improving human performance.

The first two areas will be briefly discussed because they have been the focus of much industry research and related commercial products. The latter two areas will be discussed in more detail given that there has been less recognition of the potential benefit of digital technology to these challenges.

\subsection{Modernizing Instrumentation and Control, Information, and Human-Machine Interface Systems}

U.S. nuclear plants continue to rely on legacy analog $I \& C$ systems that will be increasingly subject to reliability and obsolescence issues. Even as these systems are sometimes replaced, the full value of the 
digital technology is not typically exploited for the reasons cited in Section 2.1. And so, there remains substantial opportunity to improve reliability and further improve safety by systematically replacing these legacy systems in a manner that captures the full benefit of digital technology. And, in regard to obsolescence, there is opportunity to replace these systems before critical parts and technical support are no longer available.

Replacing these systems is often economically marginal when done on a like-for-like basis. So when utilities do undertake these types of replacements, they usually rationalize the investment as just the cost of staying in business (i.e., a "maintenance" capital investment). Because they are like-for-like, resulting in essentially the same capability, there is no broader performance gain for the plant.

However, when these systems become part of an integrated digital platform, far greater economies can be extracted, both in plant operations and plant support activities. Under such a concept, capabilities can be derived that improve many aspects of plant performance, not just the technical performance of the replaced systems.

\subsection{Managing Plant Assets to Support Long-Term Operations}

Asset management has become a key focus of the nuclear power plants, especially in view of the extended operating licenses. Many of the key components and structures were designed for a 40-year life, which has been extended to 60 years for many of the domestic plants and may possibly be extended to 80 years. Modern digital diagnostic and monitoring technologies can play a significant role in protecting these assets by identifying when and where intervention is needed. Also, they can play a critical role in justifying the extended life of the assets on a technical basis.[4]

There are numerous areas of the plants that can benefit from these technologies, including concrete, cables, high-performance metals, power equipment (motors, transformers), and underground piping. With online diagnostic technologies, these components and structures can be monitored by remote technical resources, relieving the operating plant of having to have these types of expertise onsite. These technologies can also enable significant cost reductions by shifting from periodic to condition-based maintenance.[5]

\subsection{Reducing Dependence on a Large Highly-Skilled Workforce}

Current plant operations are labor-intensive due to the vast number of operational and support activities required by the legacy technologies. The work is accomplished using an in-house workforce of operators and technologists with specialized expertise in the existing systems and facilities. And, many different types of expertise are required to be available directly onsite or close by, due to the typically short time available to correct problems to avoid shut-downs or restore regulatory compliance.

Labor is typically the single biggest item in the O\&M costs of a nuclear plant. A nuclear plant has approximately ten times the number of staff as a similarly sized coal plant. And the costs are much broader than simply the salaries and benefits of the workers. There are constant additional costs in recruiting, hiring, and training when expertise is lost due to attrition.

Going forward, there are concerns whether the nuclear industry will even be able to attract the needed engineers and technicians into careers centered in these legacy technologies. It will likely have to offer salary premiums to retain them, further exacerbating the cost of labor. And since these technologies are no longer taught in schools, it will fall to the nuclear operating companies to teach and maintain these specialized skills. All of these additional support requirements just compound the staffing problems.

On a societal level, it is expected that in the future workers will change jobs far more frequently. Moreover, typical company policies actually promote frequent lateral job changes to broaden employees for future advancement. These factors will limit the depth of expertise in the plant staff and result in a shortage of critical experts in those disciplines that require years of experience to fully master. The outcome will be a less-effective workforce in addressing time-critical problems. 
Digital technology can substantially address this escalating issue of staff cost by enabling a shift from a labor-intensive operating/support model to one that is technology-based. It can do so by displacing many of the repetitive, tedious activities that are currently performed manually. This, in turn, will greatly reduce the dependence on maintaining such a large-skilled workforce. Further, it can enable many activities to be performed remotely, thus the need for specialized experts to be on site. Rather, the operating companies can outsource this support to companies with greater expertise and experience. In this way, the nuclear power plants can maintain a smaller, more generalized workforce, trained more for operational and general support roles rather than specialized technical roles.

\subsection{Improving Human Performance}

Many industries have greatly reduced their reliance on human performance to conduct high-risk activities. Examples include advanced flight management systems for airliners, numeric control for high precision manufacturing, and advanced medical diagnosis and treatment systems for doctors. These digital applications have literally transformed how these activities are conducted, yielding amazing improvement in accuracy, quality, and efficiency.

On the contrary, for current nuclear plants, many critical activities are still performed manually due to the technological limitations of the legacy plant systems and support facilities. A reliance on human skill and decision-making is still the norm for most plant operational and support activities.

Even so, nuclear plant operators have been quite successful in improving human reliability through a variety of techniques and job aids. These have included human performance tools such as communication standards, self-checking, questioning attitude, etc. Also, a concerted focus on correct worker behaviors and adherence to formal work expectations has produced significant improvement over what the industry experienced in its early years, namely, frequent operational transients and nuclear safety challenges due to human error.

However, further plant performance improvement is now restrained by what seems to be a practical limit in human performance. Human error rates in the nuclear plants have been essentially flat for several years, after a period of notable improvement. Efforts to improve human reliability are clearly approaching a point of diminishing returns as illustrated in the following diagram.

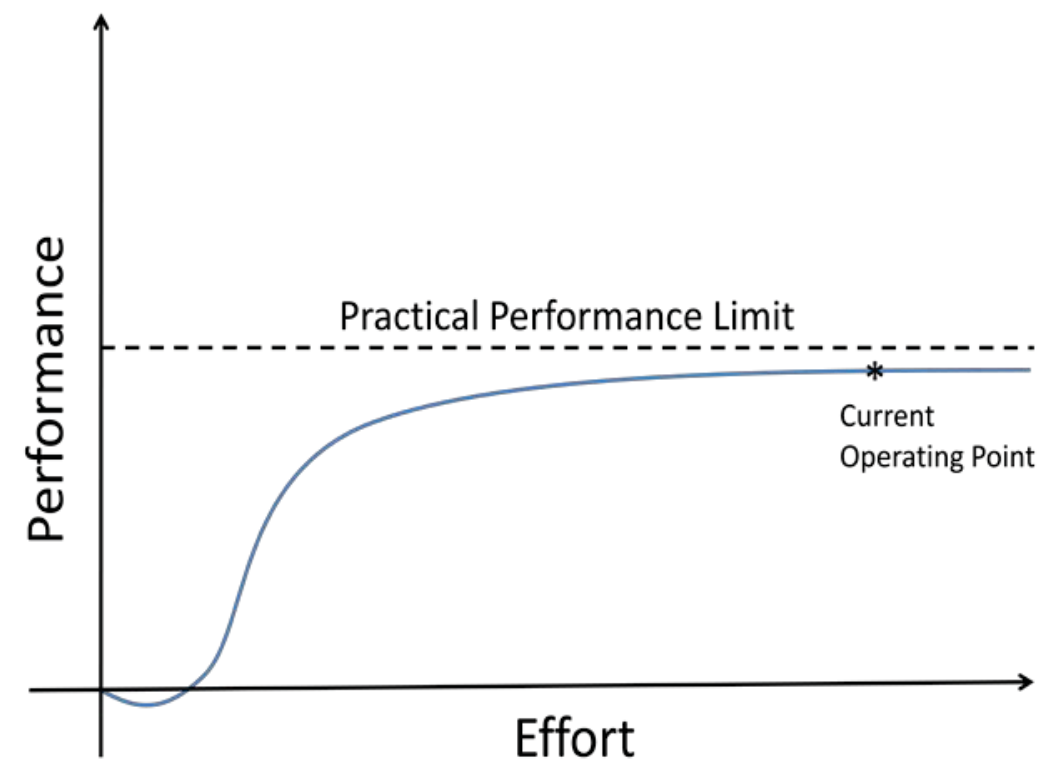

Figure 1. Practical limit of the current human performance paradigm. 
In addition to error reduction, the nuclear plants have employed a number of barriers to prevent errors from causing operational events. These have included independent verifications, enhanced job oversight, post-job reviews, and others. In spite of these barriers, there is still a residual level of human error that is challenging nuclear safety and production. In fact, in the first half of 2010, there has been a sharp increase in nuclear safety challenges caused by human error as compared to recent years.

Also, the by-product of this approach to human performance is that work processes have become overly complex. Further, the time and number of workers to perform plant support activities have significantly increased, and worker satisfaction has been eroded. In short, the cost of human error prevention has become a significant and growing part of the already high cost of labor in the nuclear plant cost structure.

To overcome this practical limit in human performance, a paradigm shift is needed in the operating/support model from one that is labor-based to one that is technology-based. The new paradigm would harness the ever-improving reliability of technology, which far exceeds human ability both in speed and accuracy. This would have the effect of shifting the operating point on the curve back to the range where effort produces highly leveraged results rather than diminishing returns, as illustrated in the following diagram. Substantial performance improvement would be possible.

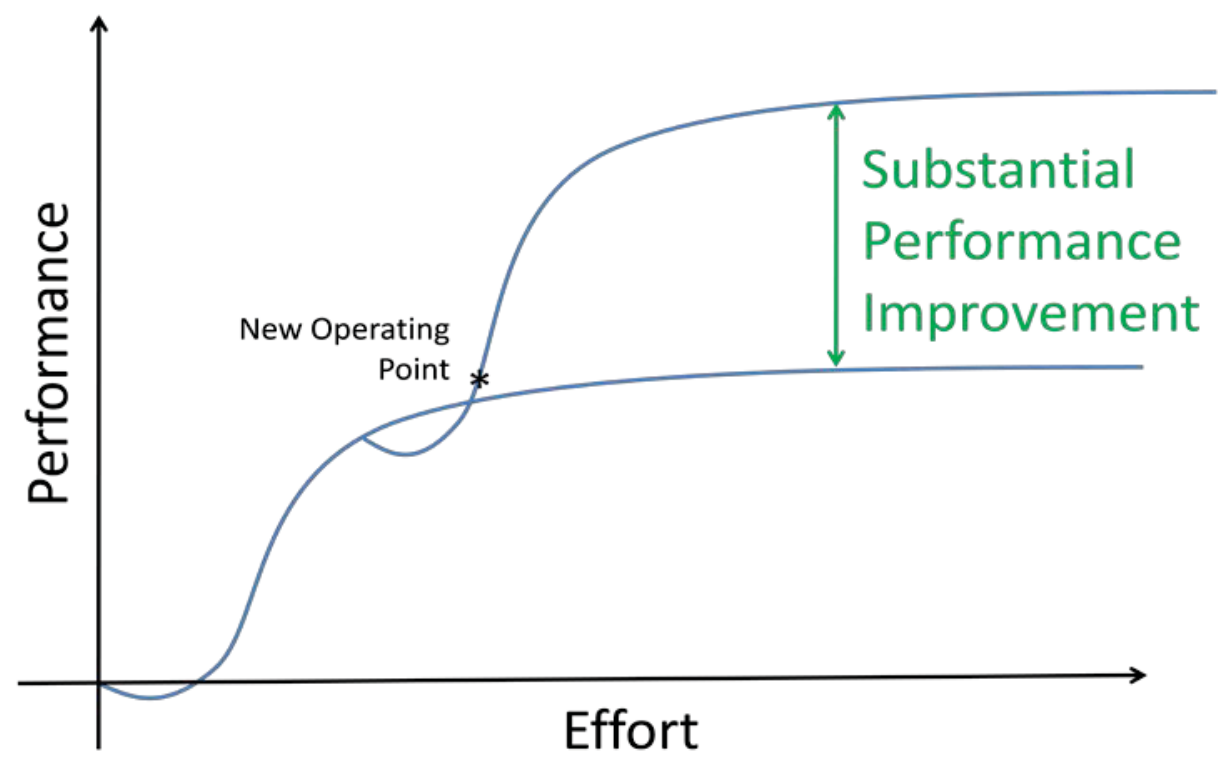

Figure 2. Performance improvement of the new paradigm.

Another consideration is the situation previously described where a digital system replaces a legacy analog I\&C system on a like-for-like basis. This is typically done to avoid changes to the existing design and licensing basis, or preserve the investment in operator training and procedures. However, this really limits the benefit of the digital system. Nominal human reliability (for action errors) is generally assumed to be at an error rate in the 1.0E-03 range [6], whereas the reliability of well-designed and maintained digital systems can approach fault rates in the 1.0E-05 to $1.0 \mathrm{E}-06$ range. When operators are left in essentially the same role even with the addition of digital systems, the human function remains the weakest link in the human-machine system in terms of overall reliability. Shifting the operator from an active control function to one of monitoring a control system could potentially improve reliability of the operation by orders of magnitude.

In short, humans are much better suited to reasoning and cognitive activities, leaving the repetitive tasks to machines. The new paradigm would optimize the use of human resources by putting them in roles suited to what they do best. The new paradigm does not de-value human performance; rather it augments human performance with technology to increase overall plant performance and reduce labor costs. 


\section{FUTURE NUCLEAR PLANT OPERATING/SUPPORT MODEL}

The future operating/support model of nuclear power plants would be one where technology has either replaced tedious human activities or rendered them unneeded. The station staff would be greatly reduced in numbers and would consist primarily of technology generalists with broad plant and process knowledge. Likewise, the number of operators would be reduced as a result of far more automated instrumentation and control systems.

The reduced plant staff would be supplemented by a seamless network of experts in supporting organizations, alerted, and activated by the plant diagnostic systems. Research is needed to define an open-system protocol for sharing plant data for analysis and direct plant support.

To complement the contribution of digital I\&C technology, advances in material science would enable system and component upgrades of much higher reliability and requiring less ongoing testing and maintenance. These would be made of materials that are corrosion and heat resistant, reducing the need for corrosion protection, lubricating systems, cooling systems, etc. This would eliminate even more work activities.

In the end, a business model would emerge that would be cost-competitive with all other forms of largescale energy production going forward. It would have lower labor costs while improving safety. This would ensure sustainability of the LWR fleet well into the $21^{\text {st }}$ century.

\subsection{Defining the Path Forward}

To address both near-term performance needs and long-term business model transformation, a top-down and a bottom-up analysis approach would be employed. The bottom-up approach would apply currently available technology to most pressing performance problems of the current LWR fleet. These types of opportunities are presented in Section 4.2.

The top-down approach would consist of analyzing the individual work activities of the current operating/support model to transform them through the application of advanced technologies. The method would involve analyzing the individual tasks to determine in what ways they can be eliminated or reduced, both in work effort and frequency. Also, the analysis would determine in what ways the activities are susceptible to human error and how this can be reduced. The product of the analysis would be a revised activity methodology with reduced workforce requirements and reduced contribution to consequential human error.

This process would be repeated for each activity under a given plant discipline until the entire work load had been exhausted. The cumulative labor offsets would be used to quantify reductions in staffing under the new model. The avoided errors would be used to estimate the improvement in safety and production.

As core work activities are eliminated or reduced, a secondary cost benefit would be calculated in terms of reductions in support staff. For example, in the case of maintenance workers, there is a related number of planners and schedulers (10:1 ratio). Managing these work groups requires a set number of supervisors (15:1), managers (50:1), trainers (50:1), process specialists (100:1), human resource representatives (200:1). Reducing core workers, either directly with technology or indirectly to outsourced experts, leverages overall plant support staff reductions proportionate to these ratios. This would mean significant cost savings in the life cycle costs of staff-recruiting, hiring, training, unproductive time, untimely attrition, loss of experience/knowledge, etc.

Finally, to integrate the bottom-up and top-down approaches, a path would be defined for near-term performance improvement using available digital applications to address current operational problems, while building the concept for the long-term operating/support model. Newly implemented applications in a nuclear plant would accrue until a tipping point is reached where it would make sense to pursue the future state operating/support model. As new nuclear plants are undertaken, efforts would be made to implement the future state model from the beginning. 


\subsection{Examples of Near-Term Opportunities}

Plant Status Control. Widely implement component position sensors to eliminate valve line-up procedures and the need for independent verification in configuration restoration activities. This eliminates the work effort and a continuing source of operational error.

Plant Performance Deviation. Develop a comprehensive computational model of the entire plantprimary, secondary, balance-of-plant, and electrical. Compare the actual nuclear, thermal, and electrical performance to the values predicted by the model. Diagnose the system and/or component degradations responsible for the performance deviation and alert the control room, suggesting compensatory actions if available. Automatically develop the testing and maintenance work orders to repair the function.

Computer-Based Procedures. Improve human performance with in procedure usage with error checking, verification of pre-requisites, automatic place-keeping, and verification of plant response. This technology would be applied to procedure usage in the control room and field settings.

Automated Plant Configuration Transitions. Automatically perform start-ups, shut-downs, power maneuvers, train/division swaps, test alignments, etc., with minimal operator commands and comprehensive verification that all requirements and permissives are met.

Use of Visualization. Use this for visualization of dose fields, display of real-time plant data during walkdowns, intuitive displays of operator information, etc.

Data Protocols for Standard Analysis. Implement remote communication technologies and plug-and-play applications, so that consulting engineering firms can support the plant with the same efficiency as currently done by direct plant staff.

Work Management System Interface with Real-Time Configuration Model. Permits real-time risk monitoring, automated work authorization, automated work scheduling, contingency analysis, avoidance of work conflicts, verification of protected trains/divisions, etc. This would also address the difficult task of monitoring shutdown configuration for technical specification compliance and risk minimization.

Automated Operator Rounds. Directly collect all the data that is currently obtained on operator rounds through enhanced instrumentation. Plant walk-throughs will still be necessary to assess general plant conditions, but will not be delayed due to manual data collection.

Alarm Management/Event Diagnosis. Replace the current alarm systems (annunciators, alarm logs, status lights, bi-stable indications, etc.) with an event diagnostic system and an audible announcement capability for plant events (as opposed to alarms based on symptoms). A system such as this would more quickly take operators to the needed recovery actions (if not automatically executed) relative to the time it now takes to work through symptom-based procedures. An intelligent alarm system could also prioritize alarms, presenting critical alarms for the given event and suppressing inconsequential alarms, to reduce the information overload on the control room.

Expanded Condition-Based Monitoring. Expand the use of this concept by using enhanced instrumentation and new predictive technologies. This will reduce labor requirements by eliminating needless testing/maintenance and the risk of error in restoring from test configurations.

\section{CONCLUSIONS}

The domestic nuclear power industry has positioned itself for a significant revival as a primary source of energy in the future. However, in spite of the impressive improvement that has been accomplished with the current operating/support model, further improvement will be limited due to dependence on certain factors: outdated plant technology for critical plant systems, long-term management of assets, potential shortages of skilled labor, and continued dependence on flawless human performance. 
Digital technology has the potential to dramatically improve each of these areas and, in aggregate, transform the operating/support model from one of labor-based to technology-based. In doing so, the nuclear power industry will be positioned to attain further improvement in nuclear safety and production, and thereby compete successfully with new forms of energy production.

The Working Group on Advanced Instrumentation, Control and Information System Technology for the LWR Sustainability Program will assist this transformation by sponsoring projects that will demonstrate the full potential of digital technology. Further, it will sponsor research to define a future operating/support model and the logical pathway to attain it. In this way, it will undergird the national effort to ensure the sustainability of the LWR fleet as part of the long-term national energy supply.

\section{REFERENCES}

1. DOE, Light Water Reactor Sustainability Program Plan, Fiscal Year 2009, September 2008.

2. Hallbert, B. P., J. J. Persensky, C. Smidts, T. Aldermir, J. Naser, Report from the Light Water Reactor Sustainability Workshop on Advanced Instrumentation, Information, and Control Systems and Human-System Interface Technologies, INL/EXT-09-16631, pp. 21-30 (2009).

3. Institute of Nuclear Power Operations, "2009 Annual Report,” pp. 11-14 (2010).

4. Robb, D., J. Gartner, Taking the Long View of Nuclear Plants, EPRI Journal, Spring 2009, pp. 11-13

5. L. J. Bond, S. R. Doctor, D.B. Jarrell, J. W. D. Bond, "Improved Economics of Nuclear Plant Life Management," PNNL-SA-56413, p. 2, 2007.

6. Gertman, D. I., H. S. Blackman, J. L. Marble, J. C. Byers, C. L. Smith, “The SPAR-H Human Reliability Analysis Method,” NUREG/CR-6883, INL/EXT-05-00509, Idaho National Laboratory, p. 19, 2005. 
Appendix B

\section{DOE Life Extension Workshop Transforming Plant Operations with Digital Technology}




\section{Appendix B}

DOE Life Extension Workshop Transforming Plant Operations with Digital Technology

\section{Transforming Plant Operations with Digital Technology}

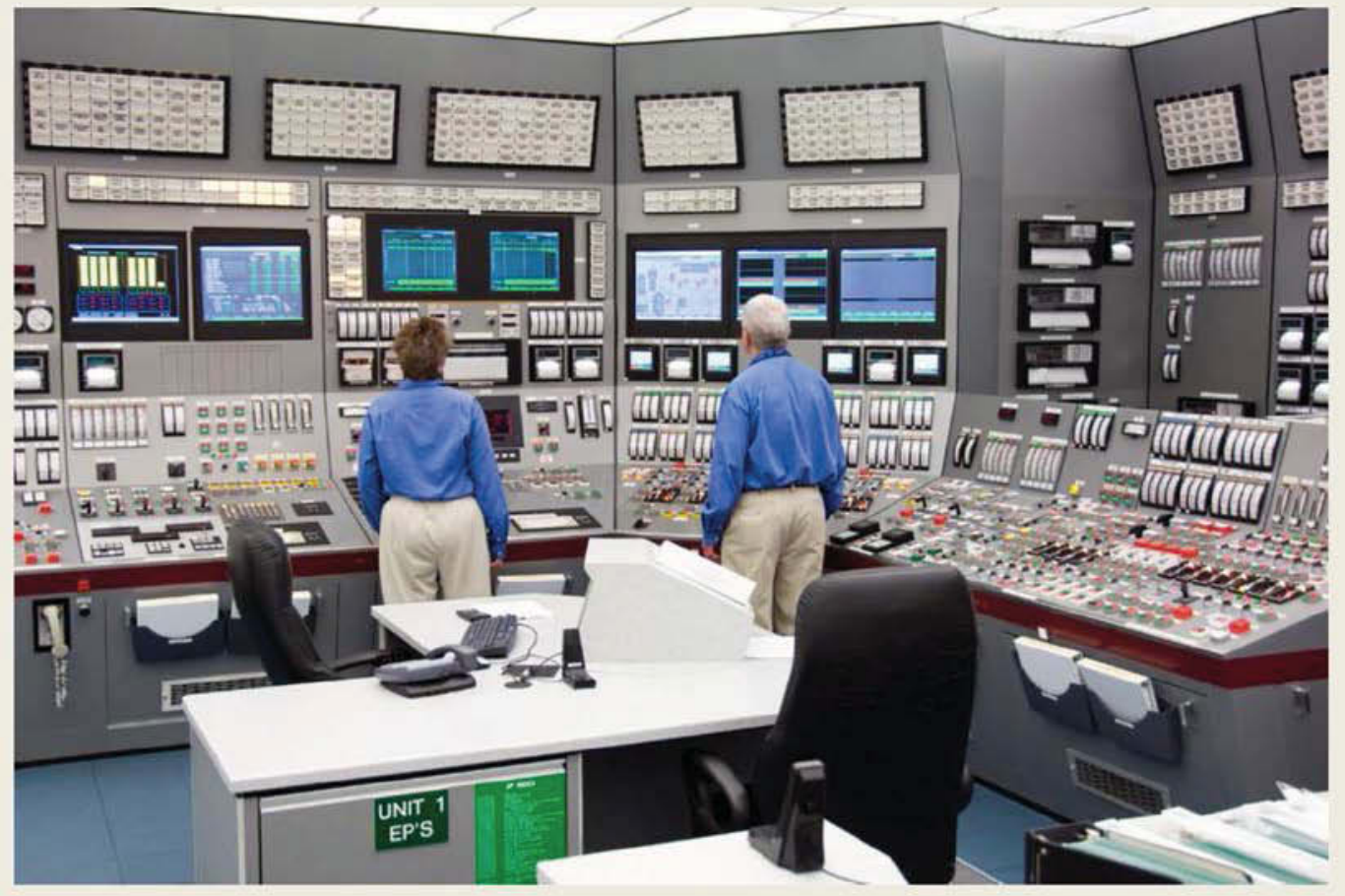




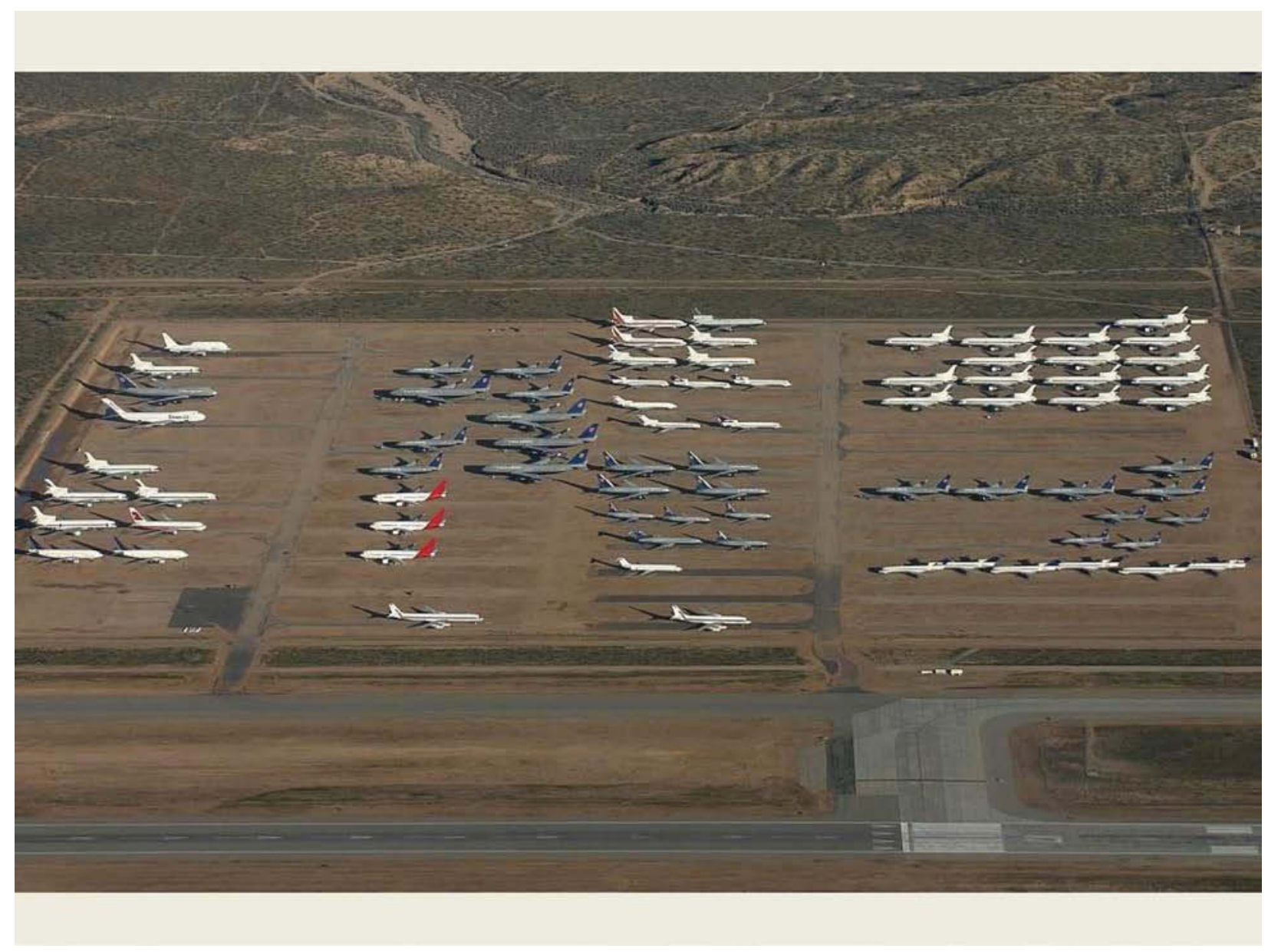




\section{Current Fleet Operating Model}

> 70's Technology

> Large Workforce

> Huge Investment in Process, Procedures, and Training

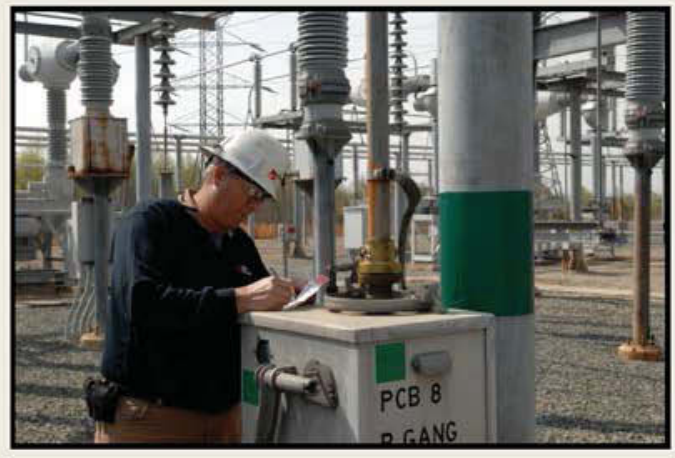

> Design \& Licensing Basis Inertia

> Safe \& Reliable Performance

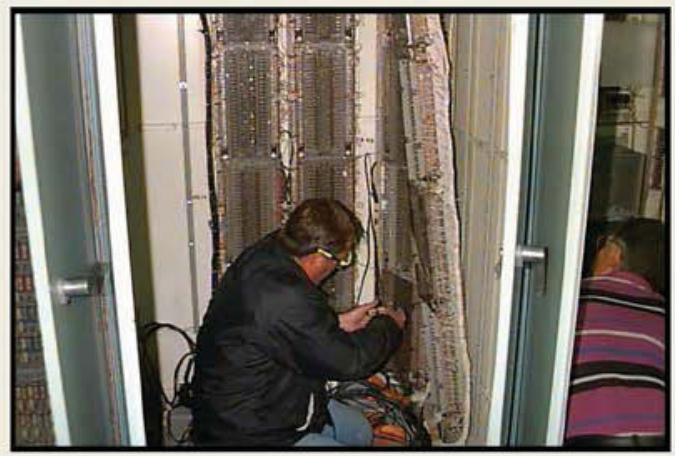




\section{Cautious Approach for Digital}

> Like-for-Like Replacements

$>$ Limited Innovation

$>$ Little Impact on Human Performance

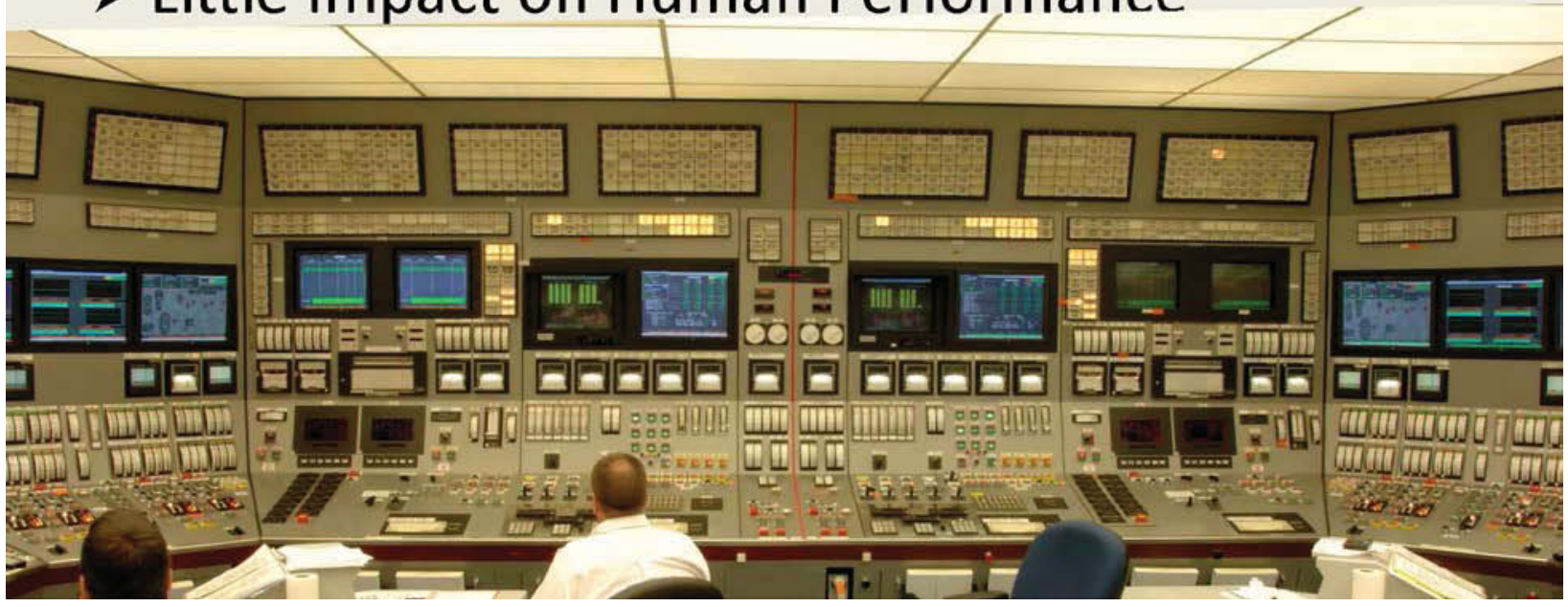




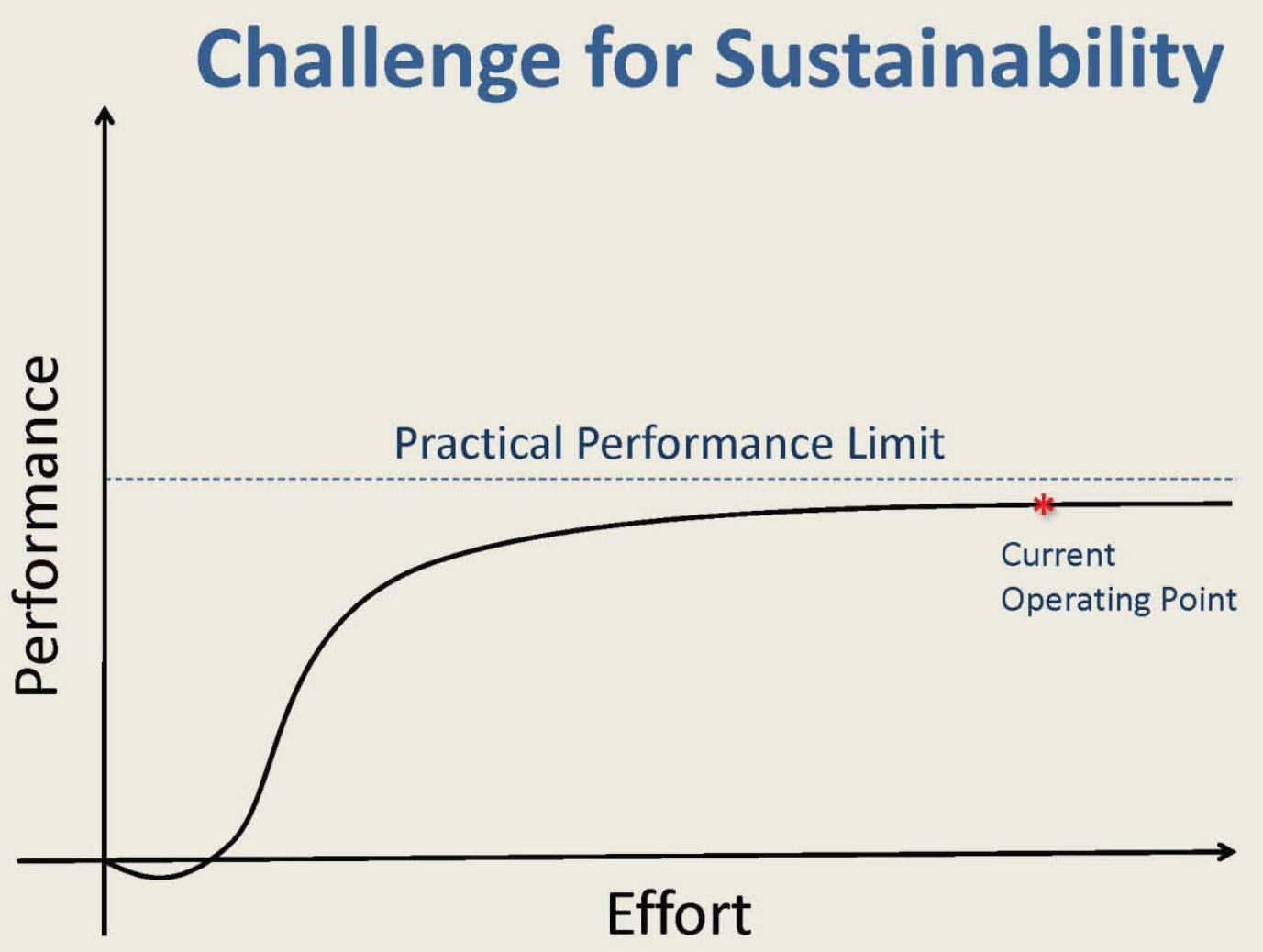


Future Performance Based on

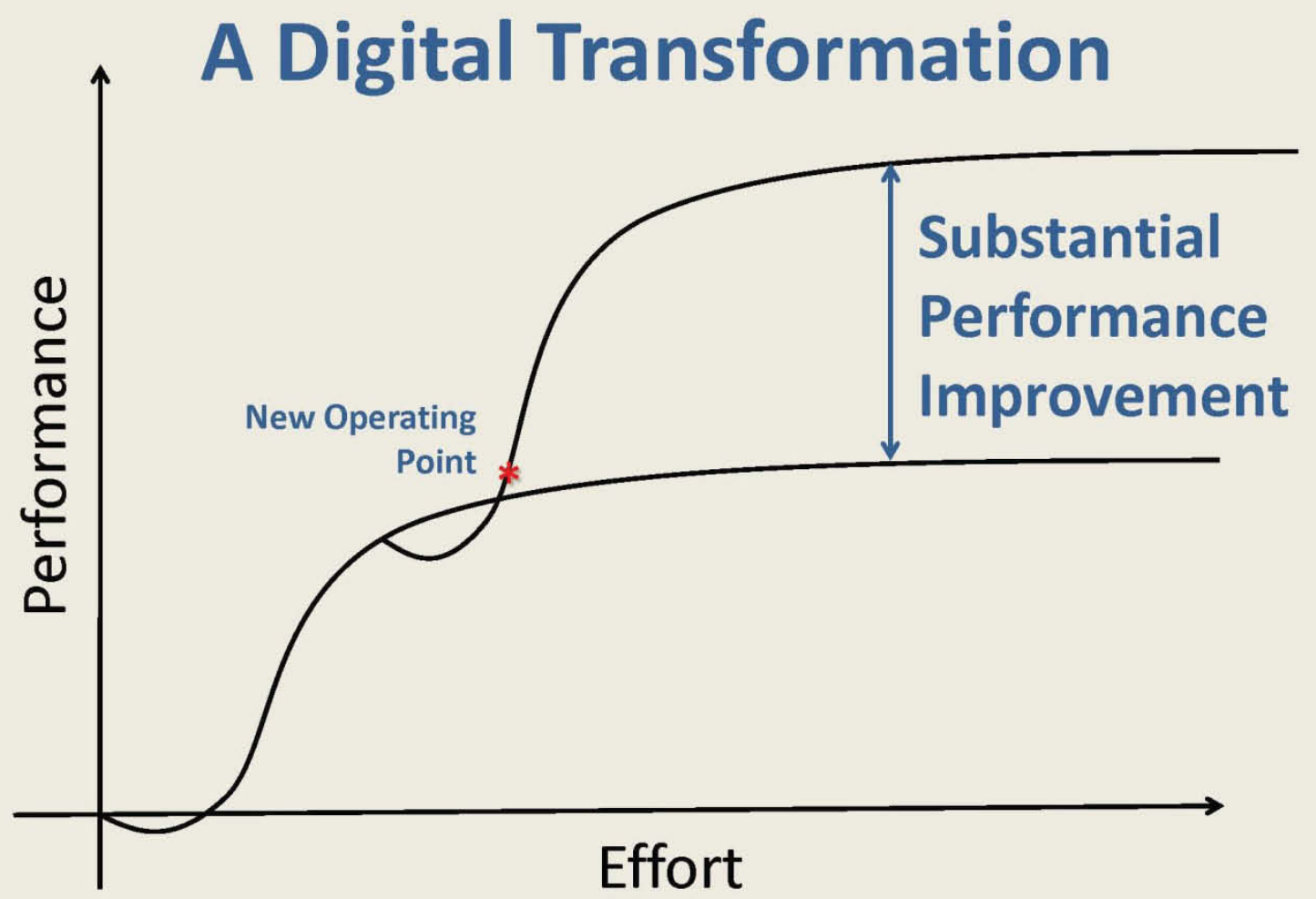




\section{Digital Transformation}

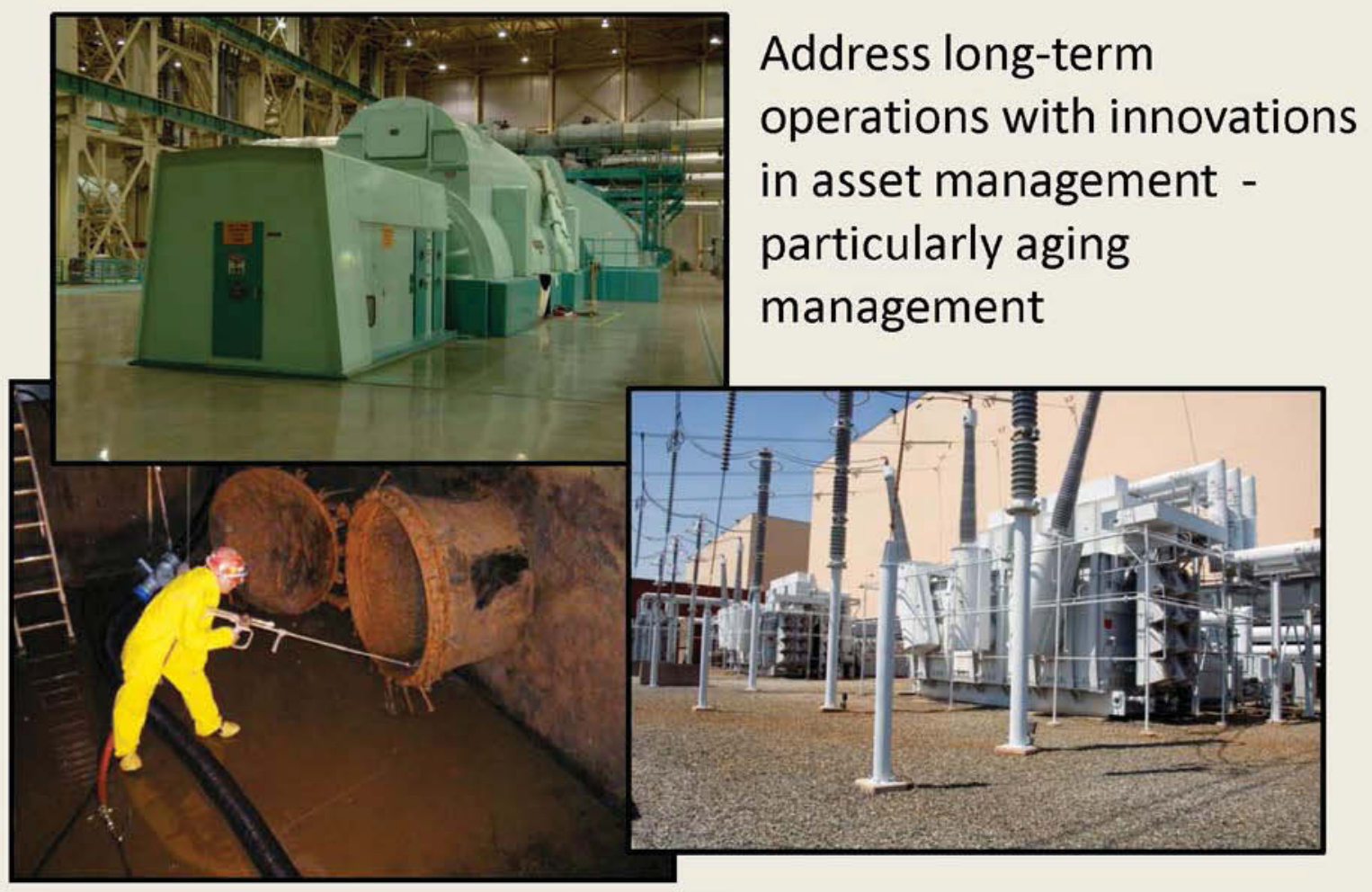




\section{Digital Transformation}

Develop advanced technologies for operational control, decision support, plant performance, configuration management, and safety oversight/margin
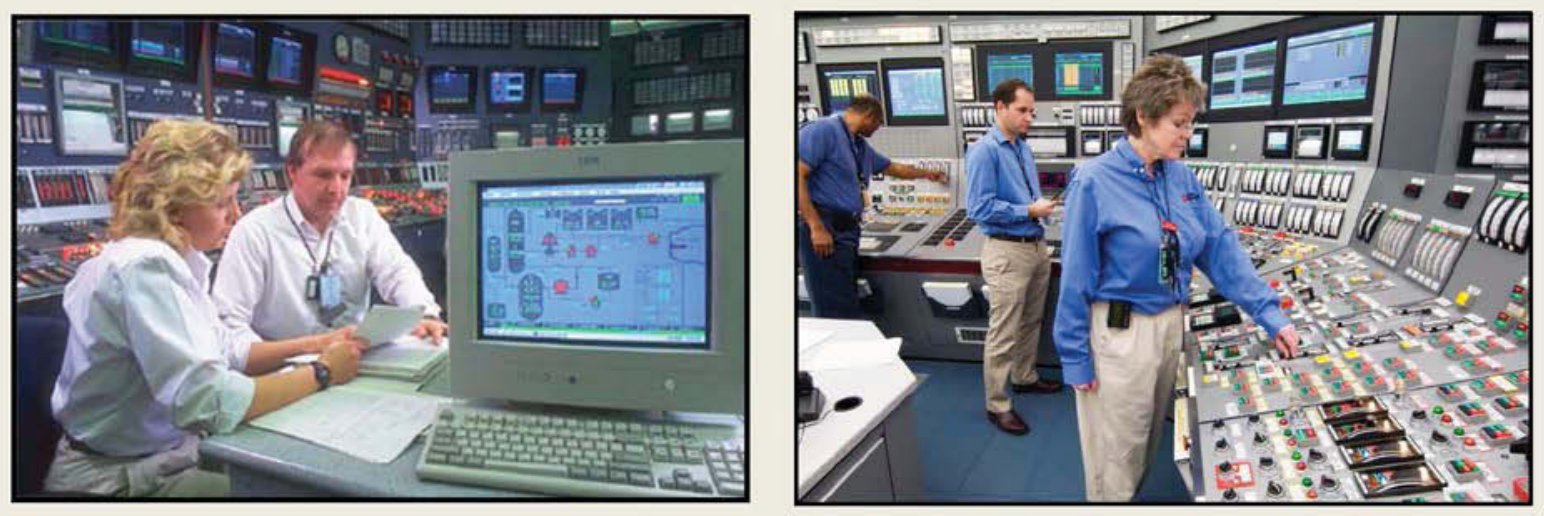


\section{Digital Transformation}

Address future shortage of qualified workers, availability of needed expertise, and job enrichment
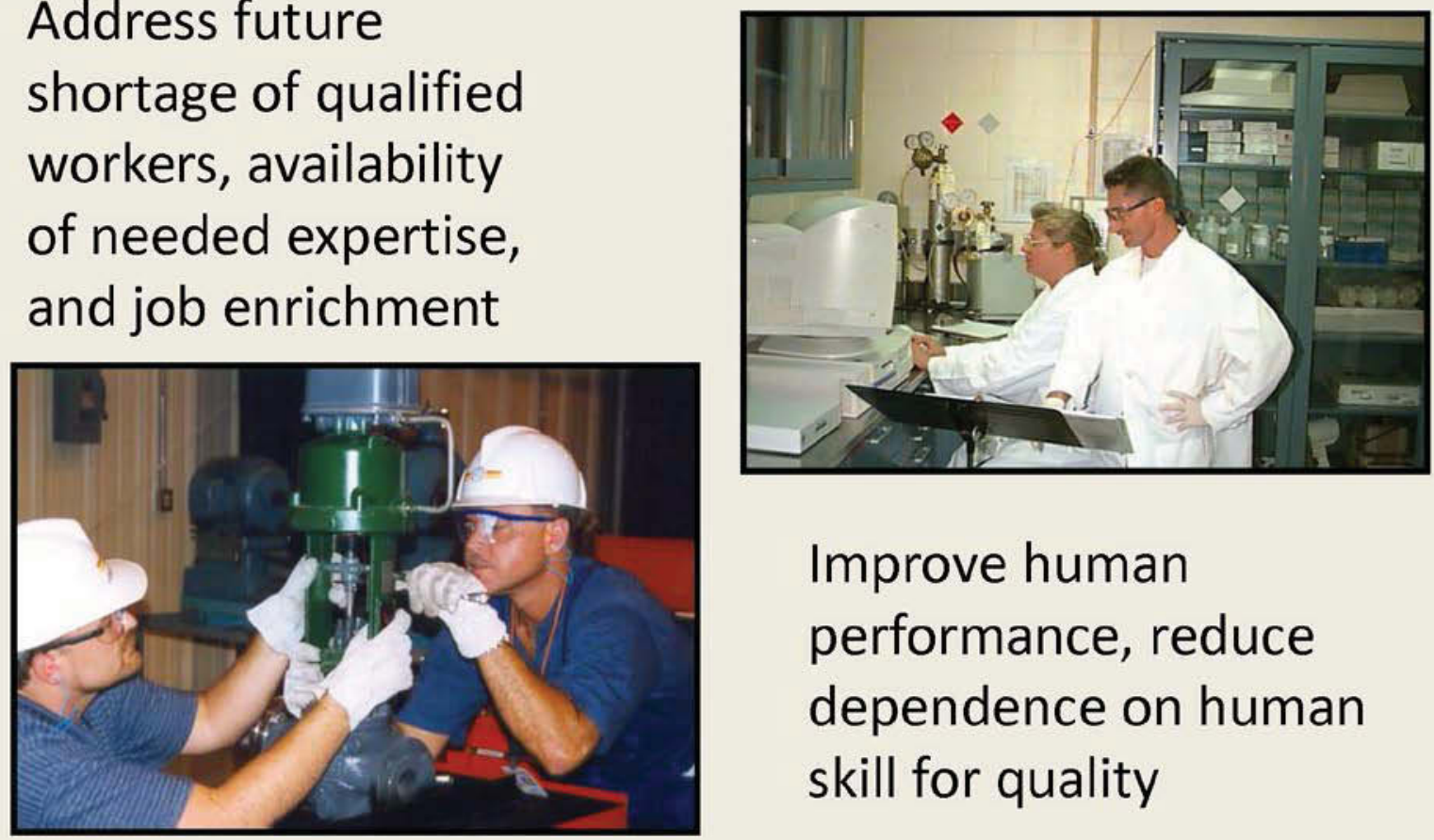

Improve human performance, reduce dependence on human skill for quality 


\section{LWRSP II\&C Working Group}

$>$ Demonstrate near-term beneficial digital applications for NPPs

$>$ Conduct research on a long-term vision of substantial digital technology integration

$>$ Communicate this work to utility and support organizations for a transformed NPP operating model based on a digital infrastructure

$>$ Coordinate research with major nuclear industry support organizations 
Appendix C

\section{Working Group Vision Document}




\section{Appendix C}

\section{Working Group Vision Document}

\section{Working Group on Advanced \\ Instrumentation, Control, and \\ Information System Technology}

DOE Light Water Sustainability Program

KEN THOMAS, FRANK LIPINSKI, TED QUINN,

DR. BRUCE HALLBERT, DR. JOSEPH NASER 


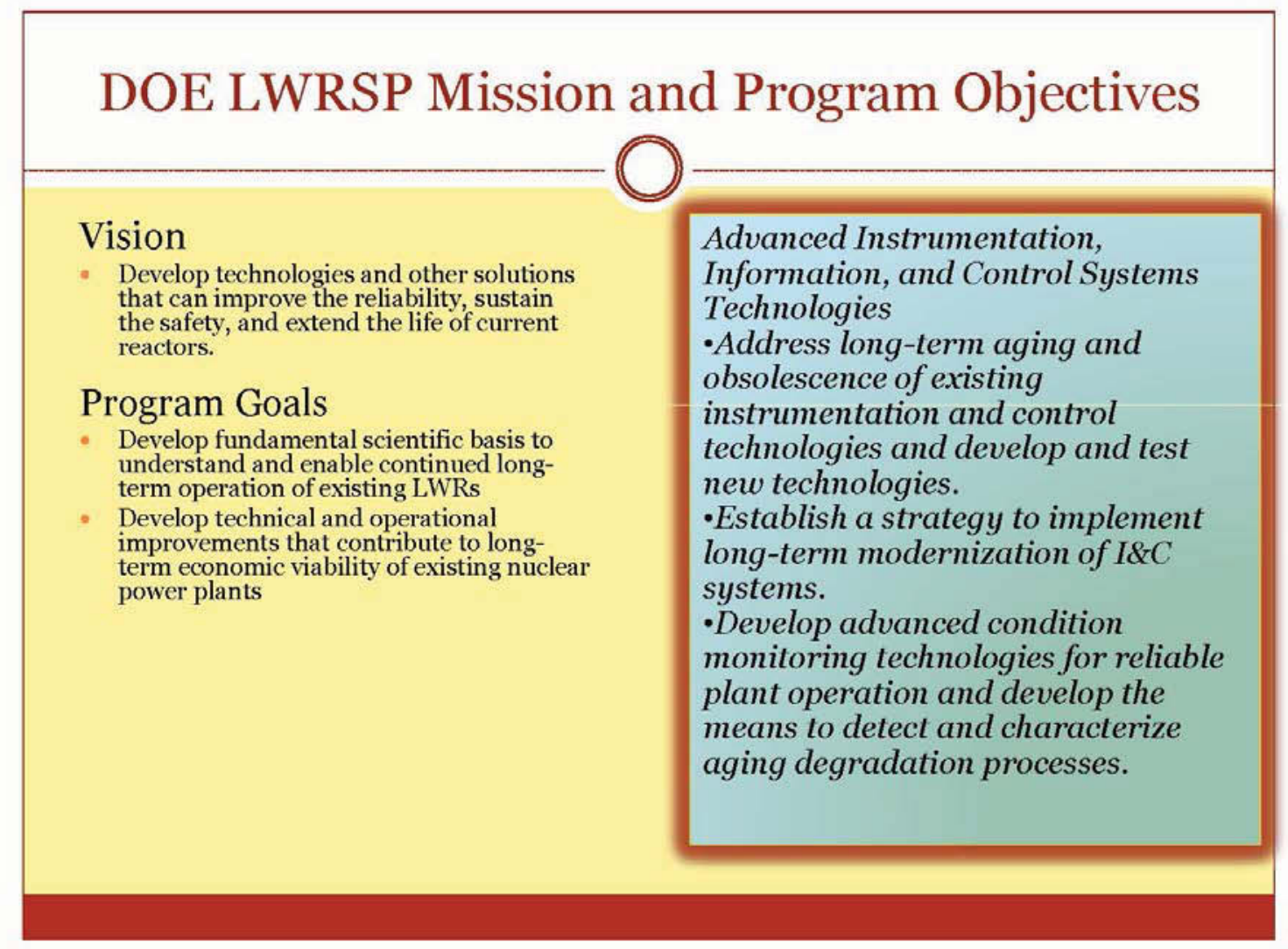




\section{Origin of the Working Group}

- 2009 Workshop held at Ohio State:

"Instrumentation and Control, Human System

Interface, and Information Technology

Requirements for Nuclear Power Long-Term

Operation"

- Common Theme: Need for a research program to develop a path forward for wide-scale digital modernization

- Working Group formed to pursue industry pilot projects in support of the research program 


\section{Purpose of the Working Group}

- Demonstrate near-term beneficial digital applications for NPPs

- Conduct research on a long-term vision of substantial digital technology integration

- Communicate this work to utility and support organizations for a transformed NPP operating model based on a digital infrastructure

- Coordinate research with major nuclear industry support organizations 


\section{Why This Working Group Is Needed}

- Digital has been applied incrementally, in a "like-forlike" manner, to lessen the impact on the operational "infrastructure" (procedures, training, human factors, licensing basis, etc.)

- Digital upgrades have mainly addressed the immediate concerns of reliability and obsolescence

- Digital has not yet made a substantial impact on operating cost

- Collaborative research and demonstrations are needed to apply digital to the long-term concerns in sustainability of the current operating fleet 


\section{Digital as a "Transformative” Technology}

- Shift from labor-intensive operating model to one that is technology-intensive

- Address future shortage of qualified workers, availability of needed expertise, job enrichment

- Reduced dependence on human skill for quality

- Address long-term operations with innovations in asset management - particularly aging management

- Develop advanced technologies for operational control, decision support, plant performance, configuration management, safety oversight/margin, and others 


\section{Working Group Progress}

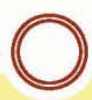

- Eight utilities actively participating

- Four meetings held in 2010

- Individual Pilot Initiatives (active or potential):

- Advanced Control Room Alarm Management

- Outage Improvement: Outage Control Center Technology

> Plant Status Control Technology

- Discussions underway with additional utilities

- Entergy \& Duke providing outreach

- EPRI coordinating industry research 


\section{Efforts Going Forward}

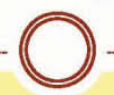

- Expand participation of utilities in the Working Group

- Define and conduct additional pilot demonstration projects

- Coordinate the demonstration projects with other related industry research

- Keep the NRC informed and involved as appropriate

- Communicate to all industry stakeholders on the progress of the Working Group and the opportunities for coordinated planning 


\section{Potential Project Areas}

- Decision Support Systems

- Plant Performance Deviation

- Computer-Based Procedures

- Automated Plant State Transitions

- Remote, On-Line Monitoring
- Use of Visualization and Virtual Reality

- Standard Interface Protocols for $3^{\text {rd }}$ Party Plant Support

- Work Management Interface with Configuration Control

- Expanded ConditionBased Monitoring 


\section{To Get Involved}

- Contact:

Dr. Bruce P. Hallbert

Director, Nuclear Safety and Regulatory Research

Idaho National Laboratory

208-526-9867

bruce.hallbert@inl,gov 


\section{Appendix D}

\section{DOE Bi Lateral Meeting Presentation for BEWG}




\section{Appendix D \\ DOE Bi Lateral Meeting Presentation for BEWG}

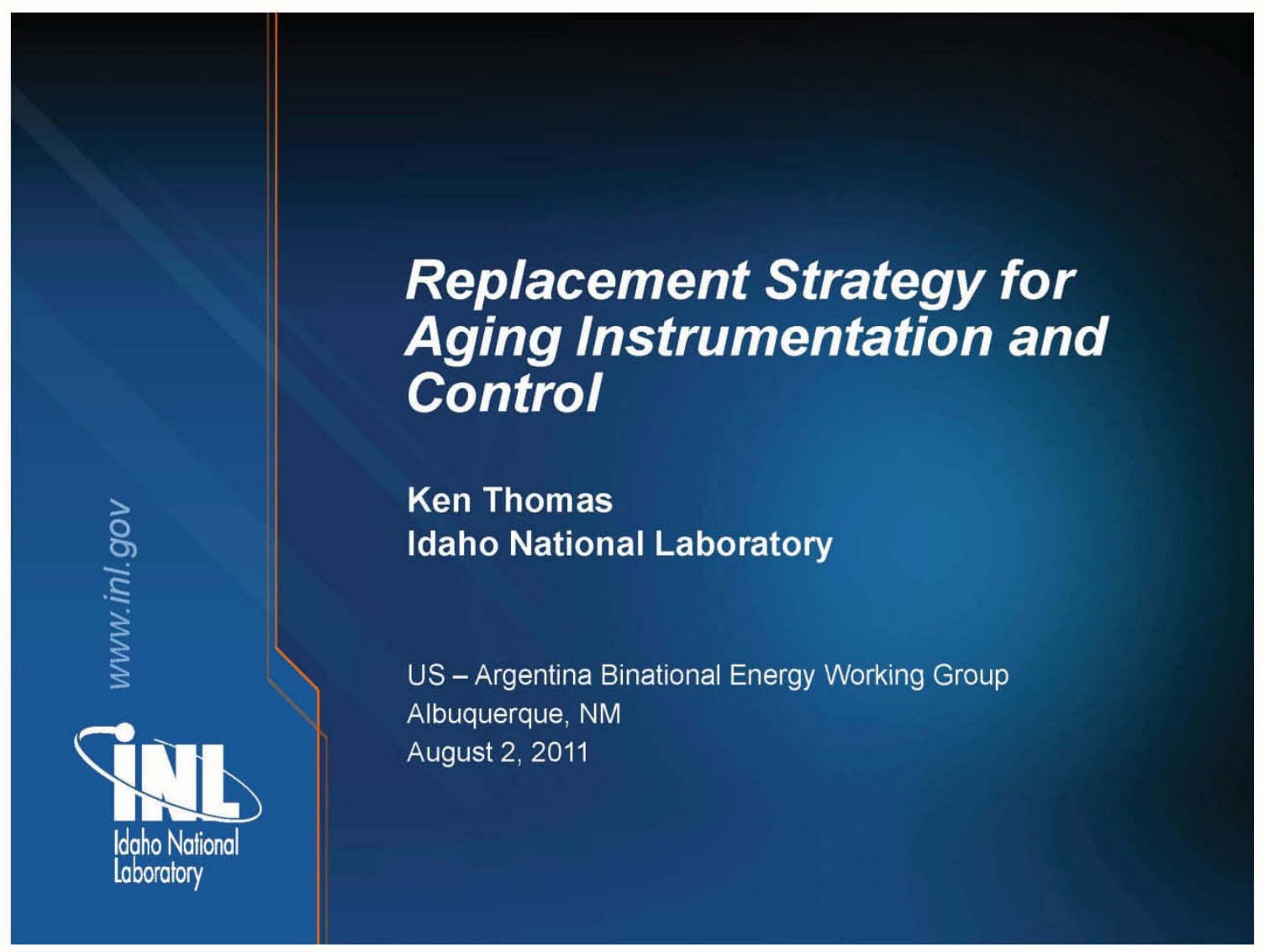




\section{I\&C Replacements with Digital Systems}

- Safety-Critical Protection Systems

- Integrated and Local Control Systems

- Monitoring Systems

- Diagnostic Systems

- Plant Information Systems

- Control Room Upgrades

- Component-Level Applications
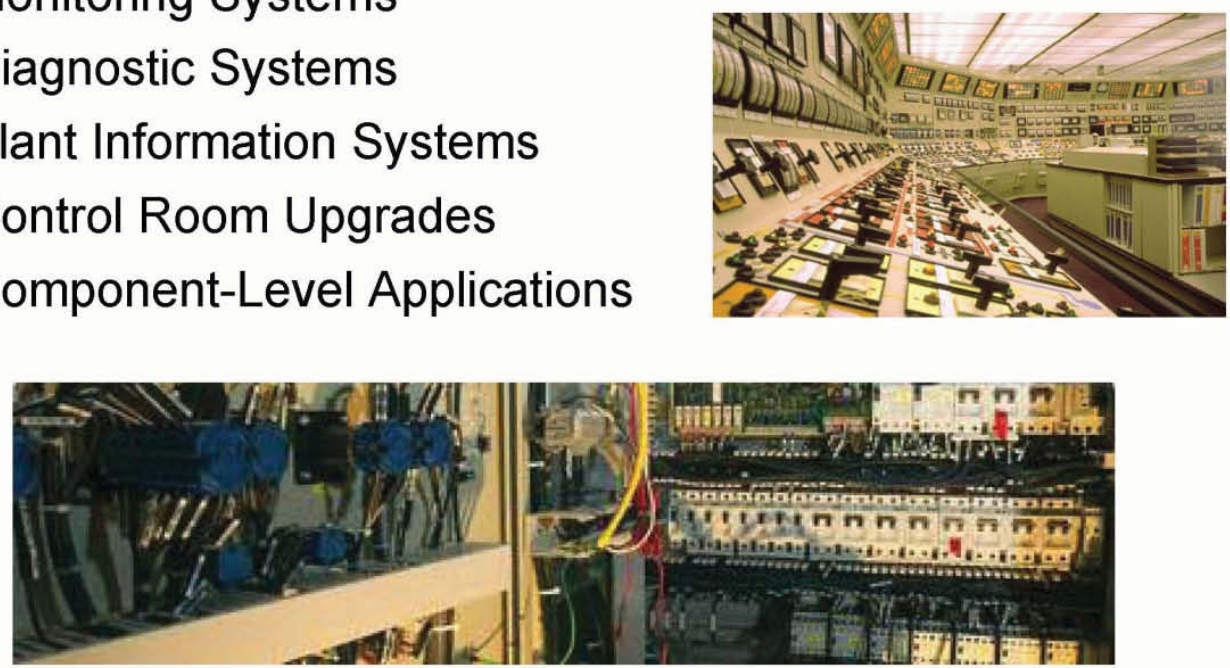


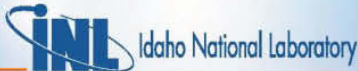

Systems-Based I\&C Replacement Strategy

- I\&C replacement strategy is driven by obsolescence and reliability issues

- Replacements are typically "like-for-like"

- Digital is not yet contributing significantly to overall plant performance improvement

- The reason is that we are thinking in terms of replacing systems rather transforming our operating model
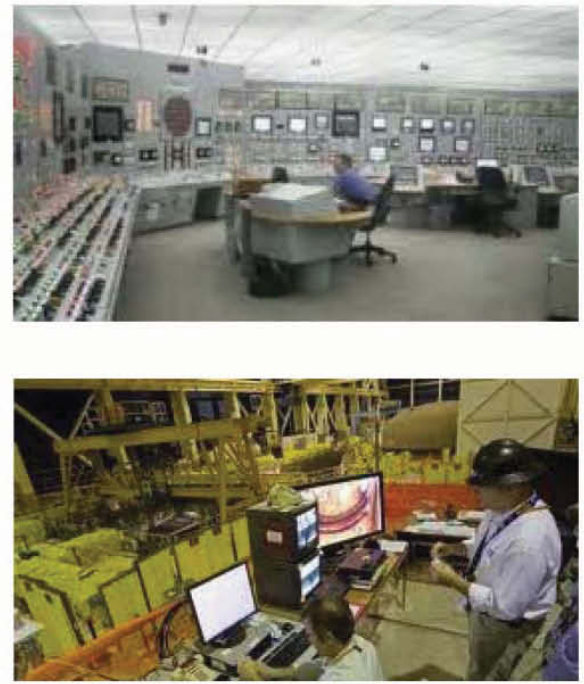


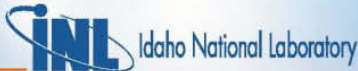 \\ Performance-Based I\&C Replacement Strategy}

- I\&C modernization is considered to be a critical need for the sustainability of the operating nuclear fleet

- Due to short-term operational focus, the US commercial nuclear industry could modernize its legacy I\&C systems and still miss the opportunity to transform its operating model

- A national research program is needed to develop the transformative technologies and implementation roadmap for a performance-based I\&C replacement strategy
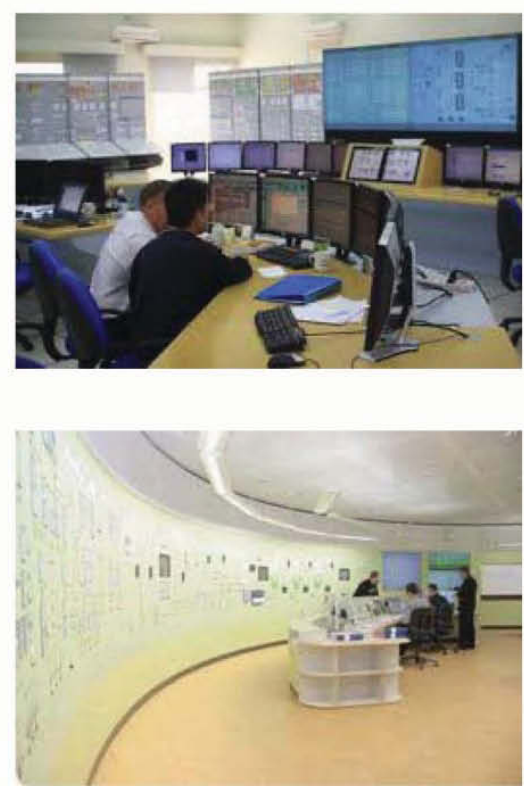


\section{Advanced II\&C Systems Technologies}

Technologies for and demonstrations of highly integrated control and display technologies that address long-term objectives of nuclear power plant operation, including the following:

- Fleet-wide management of asset information to support integrated operations

- Improved visualization and use of information to support decisionmaking and actions

- Greater automation of functions and availability of operator support systems to improve efficiencies and reduce errors

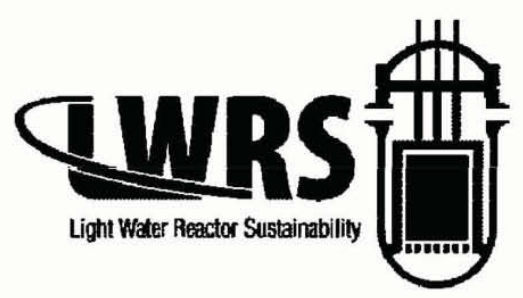




\section{Engaging the Nuclear Power Industry}

- Research and development of near-term beneficial technologies while building the digital work environment of the future

- Integrating plant systems, plant processes, and human performance

- Project definition and control using Cooperative Research and Development Agreements (CRADA)

- In-kind contribution from industry - time, expenses, plant access, plant expertise, reference documents, and other resources (e.g. simulator)

- Industry hosts the technology demonstration and effectiveness assessments

- INL provides research \& associated technologies, training \& implementation, and research reports

- INL facilitates industry-wide adoption of new capabilities

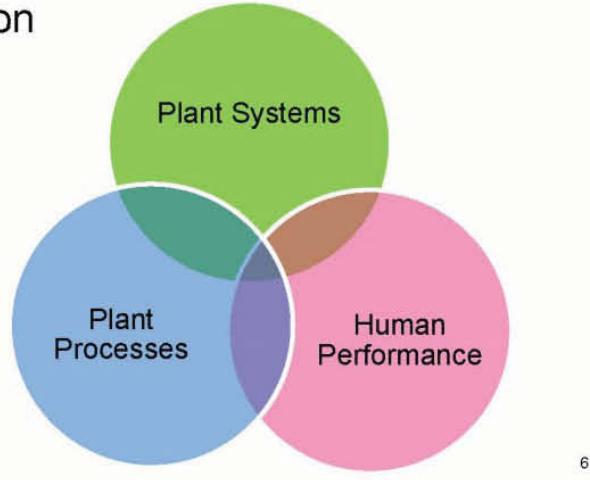




\section{Industry Working Group}

Exelun.

aps
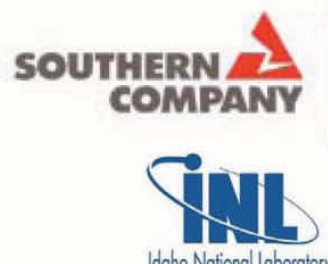

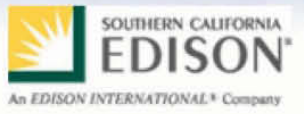

Constellation Energy

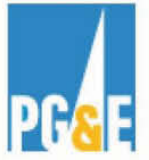

Duke Energy

\section{TIIdaho National Laboratory}

Entergy.

THE POWER OF PEOPLE.

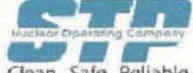

Idaho National loboratory

- Composed of innovation leaders within these companies

- Provides critical input on industry needs and long-term vision of a future integrated digital environment

- Provides opportunities for pilot projects where there is alignment with innovation initiatives within these companies 


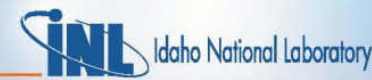

\section{Science Based Approach}

\section{Approach}

- Transformation of plant functions

- Development of enabling technologies

- Demonstration before deployment

Addresses

- Ingrained limiting paradigms

- Technology obsolescence

- Future workforce

- Human error

End-State Vision

- NPP modernization and renewal

- Extended plant life with sustainable operating model

- Enhanced nuclear safety

- Reduced staffing \& O\&M costs

\section{Applied Research Model}

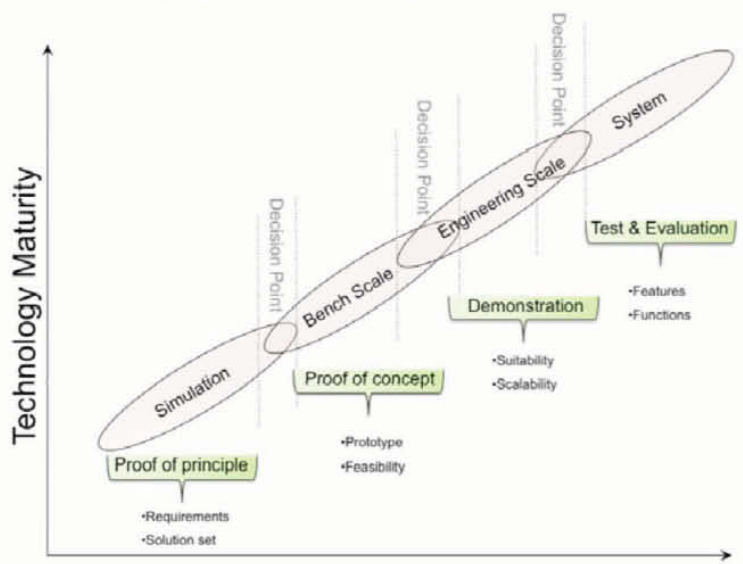

System and Data Qualification Requirements 


\section{Tild Idaho National Loboratory}

\section{Human Systems Simulation Laboratory}

- Reconfigurable Control Room Simulator

- Virtual Reality Cave

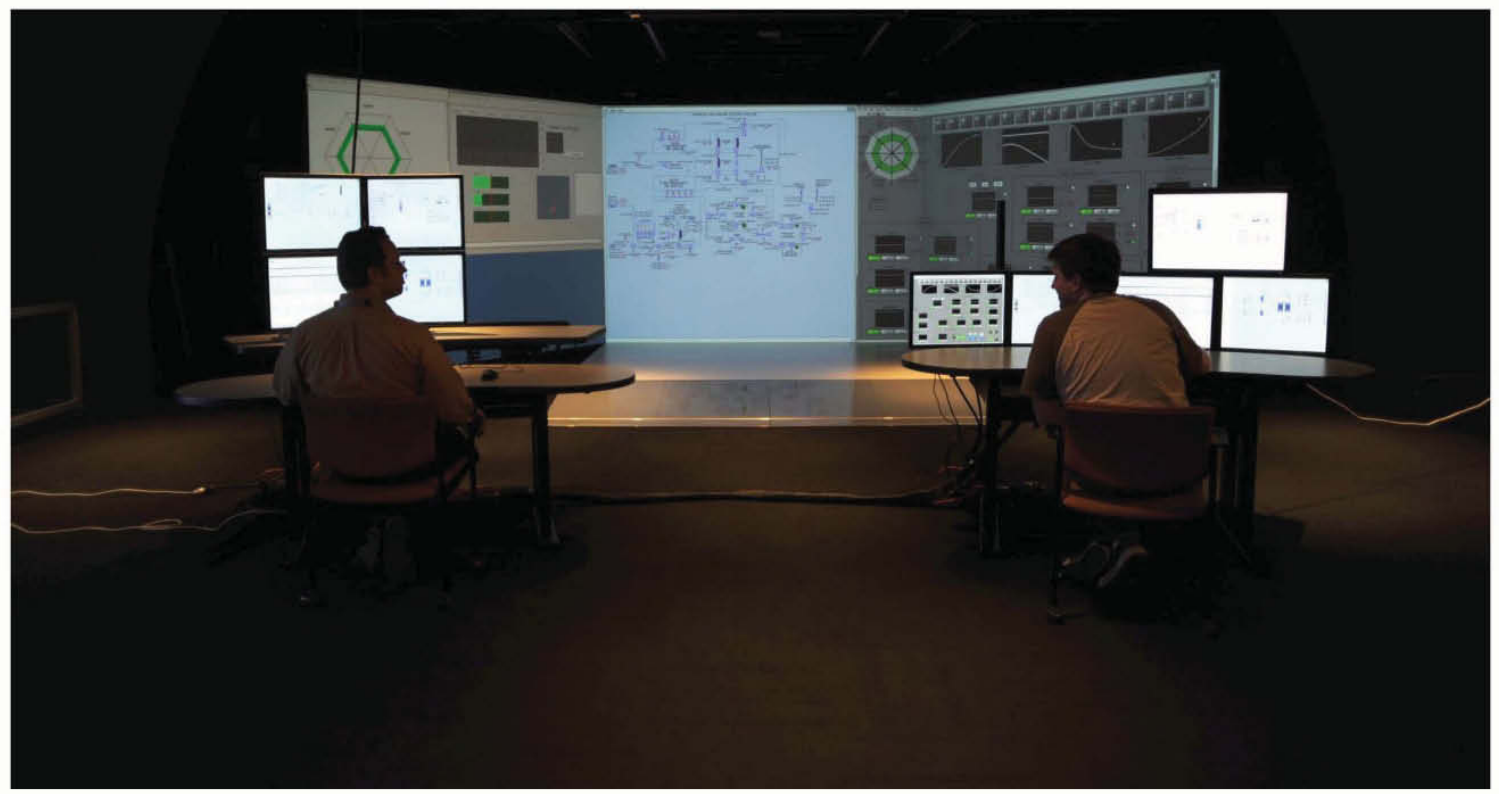


Technology Building Blocks for a Future Digital Environment

- Heads-up information displays

- Wireless streaming of information \& video

- Computer-based procedures

- Component status identification (bar code, RFID)

- Smart Board - large interactive display devices

- Wireless component position indicators

- Alarm management and display technology

- On-Line monitoring systems
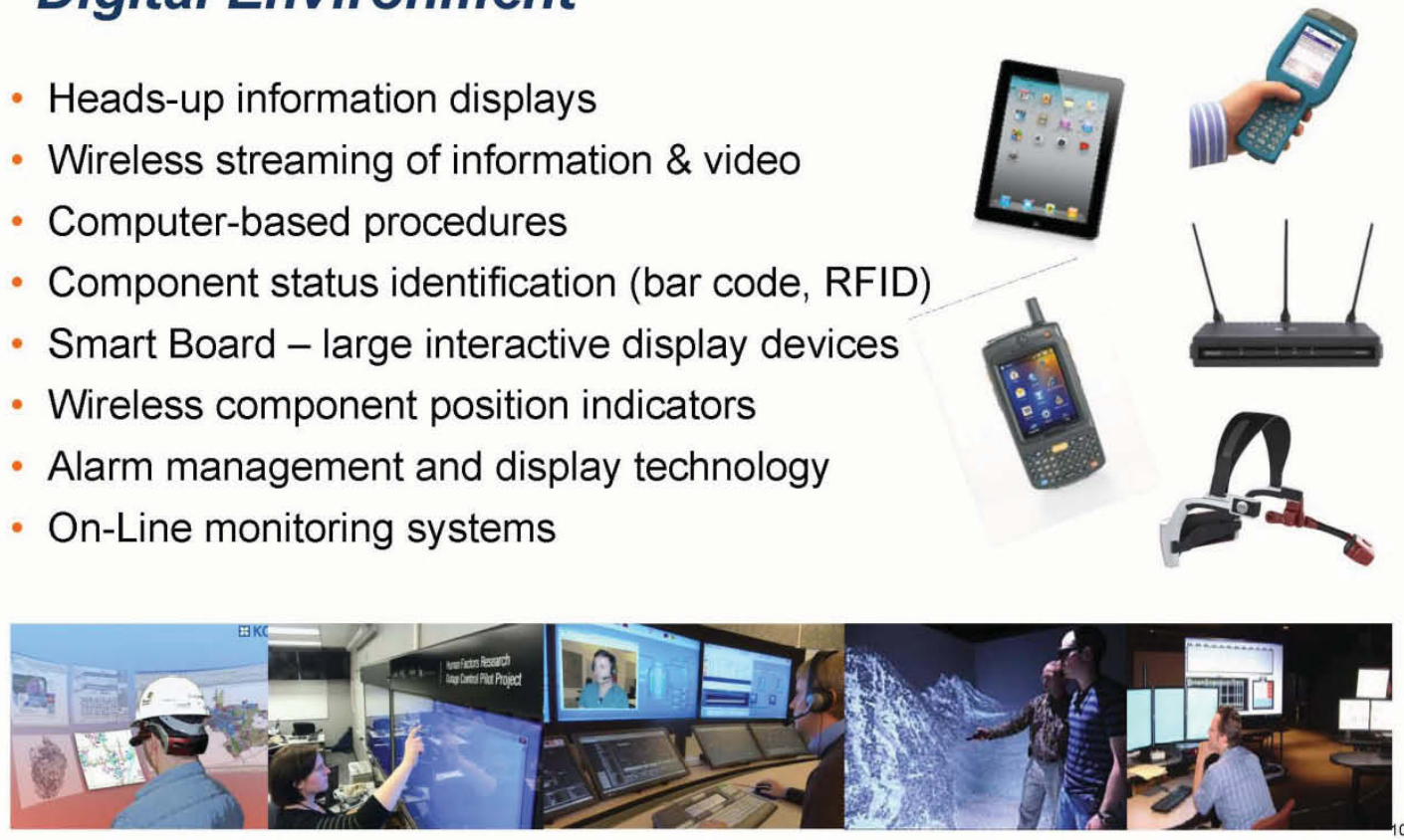


\section{Building a Seamless Digital Environment}

- Highly-Integrated Control Room

- Highly-Automated Plant

- Human Performance Improvement for NPP field workers

- Integrated Operations

- Outage Safety and Efficiency

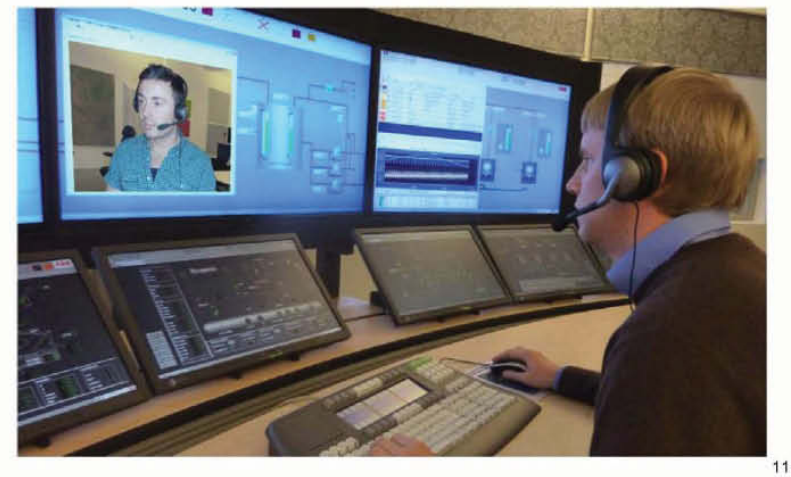




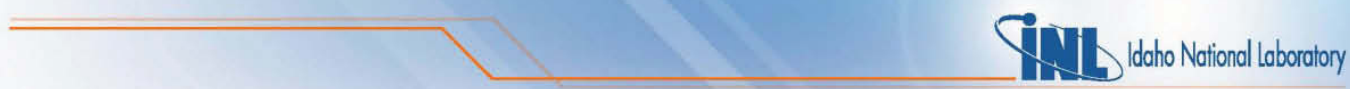
Highly-Integrated Control Room

Pilot Projects

- Incorporating Digital Upgrades in an Analog Control Room

- Advanced Alarm Systems

- Control Room ComputerBased Procedures

- Computerized Operator Support System (COSS)

- Future Concepts of Operation

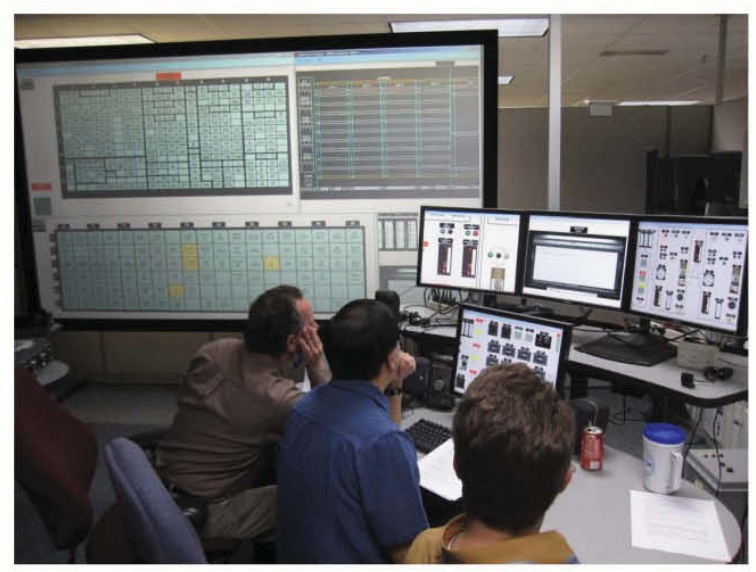




\section{High-Automated Plant}

$\underline{\text { Pilot Projects }}$

- Digital Architecture for a Highly-Automated Plant

- Automating ManuallyPerformed Plant Activities

- Advanced Plant Control Automation

- Advanced Plant Control Algorithms
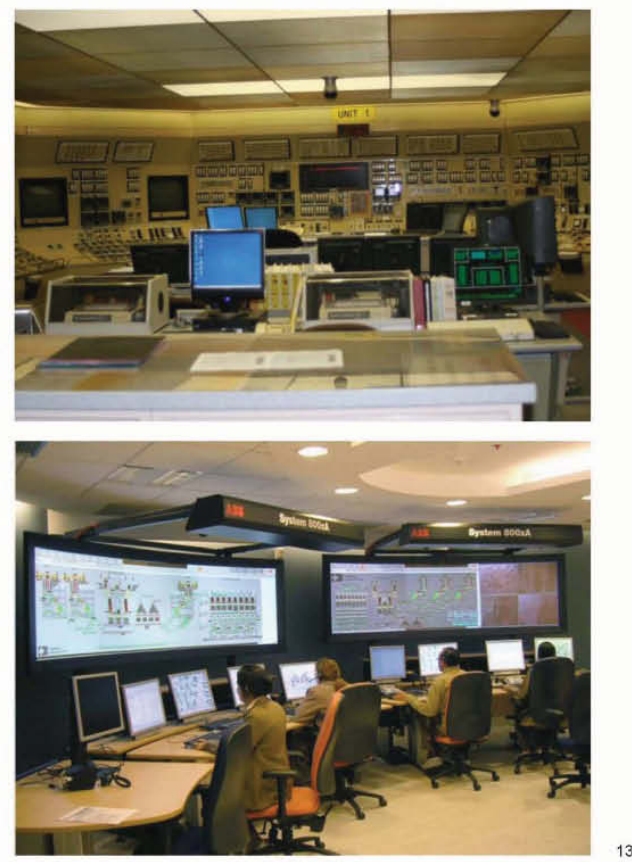


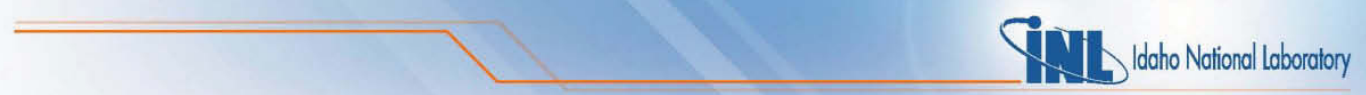
Human Performance Improvement for NPP Field Workers

Pilot Projects

- Mobile Technologies for NPP Field Workers

- Automated Work Packages

- Augmented Reality for NPP Field Workers
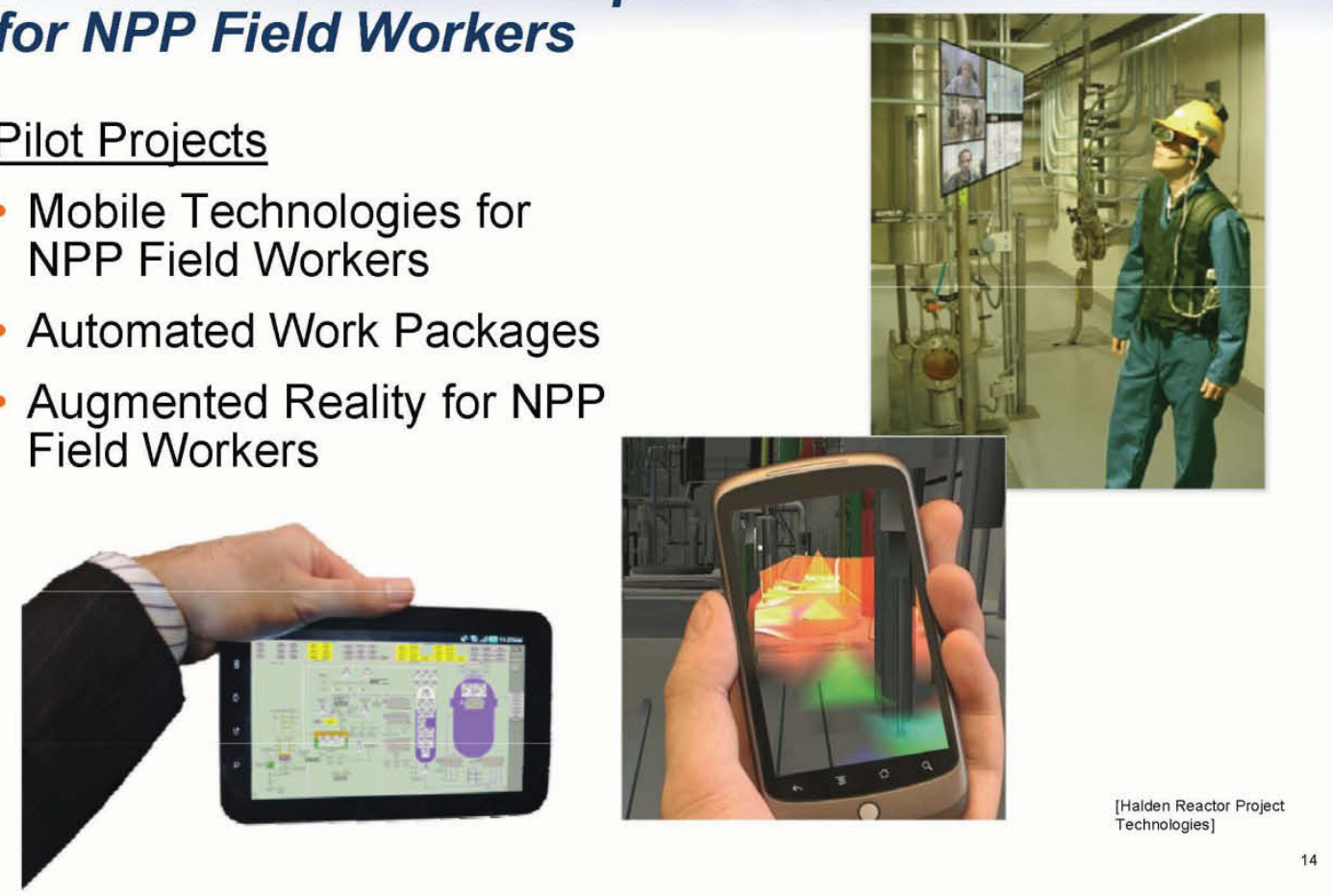


\section{Integrated Operations*}

Pilot Projects

- Advanced OLM Facility

- Virtual Plant Support Organization

- Management Decision Support Center
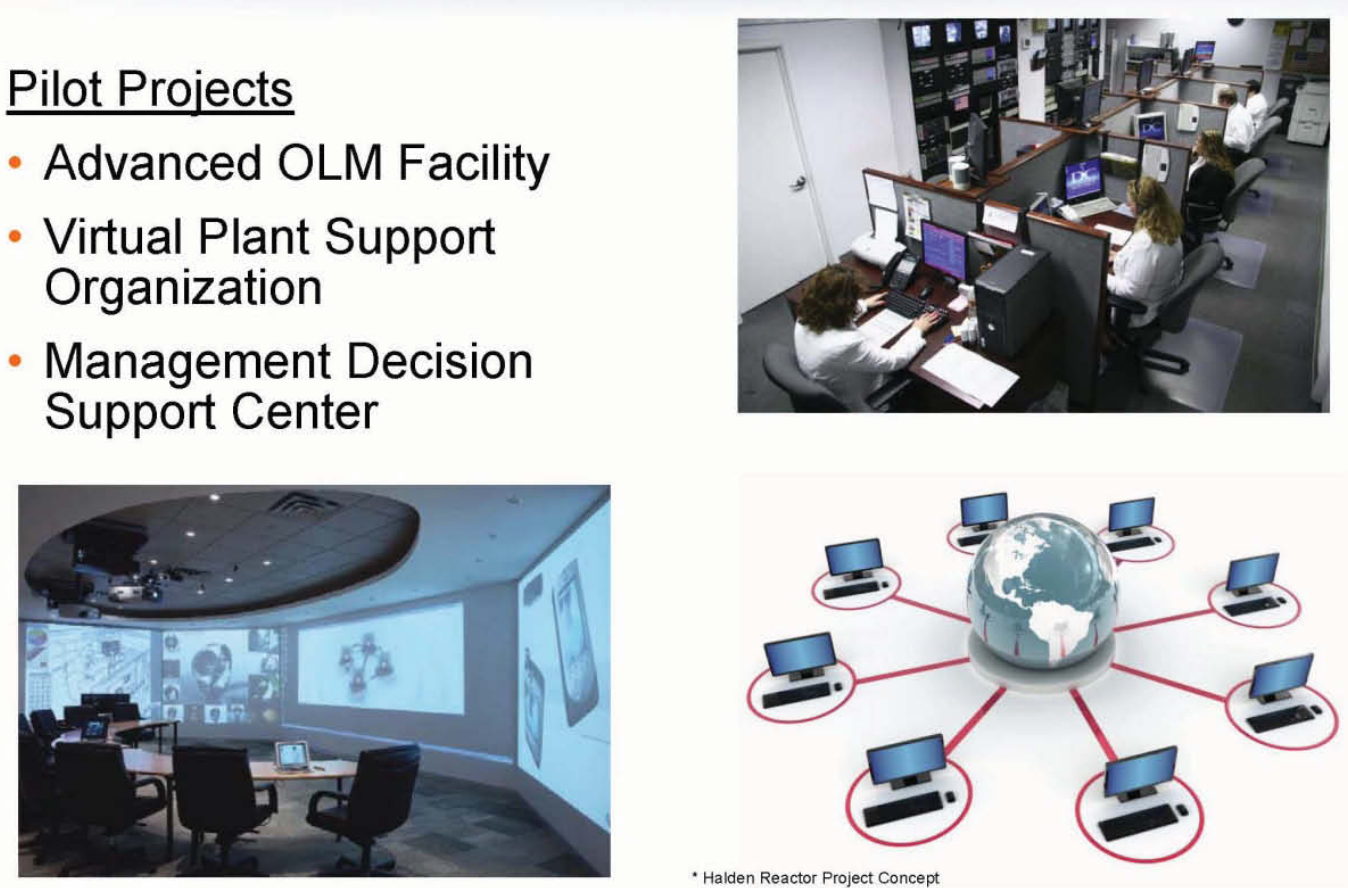

- Halden Reactor Project Concept

15 


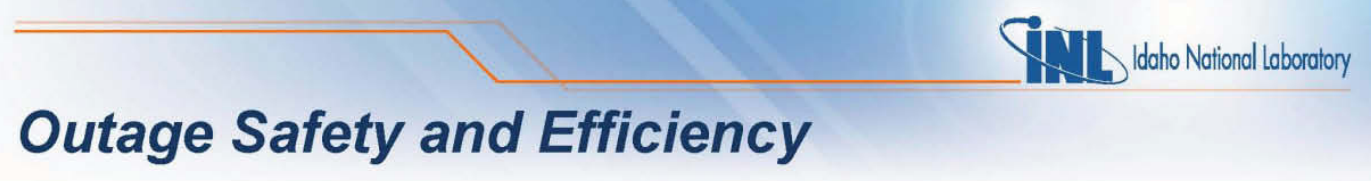

\section{Pilot Projects}

- Advanced Outage Coordination

- Advanced Outage Control Center

- Outage Risk Management Improvement
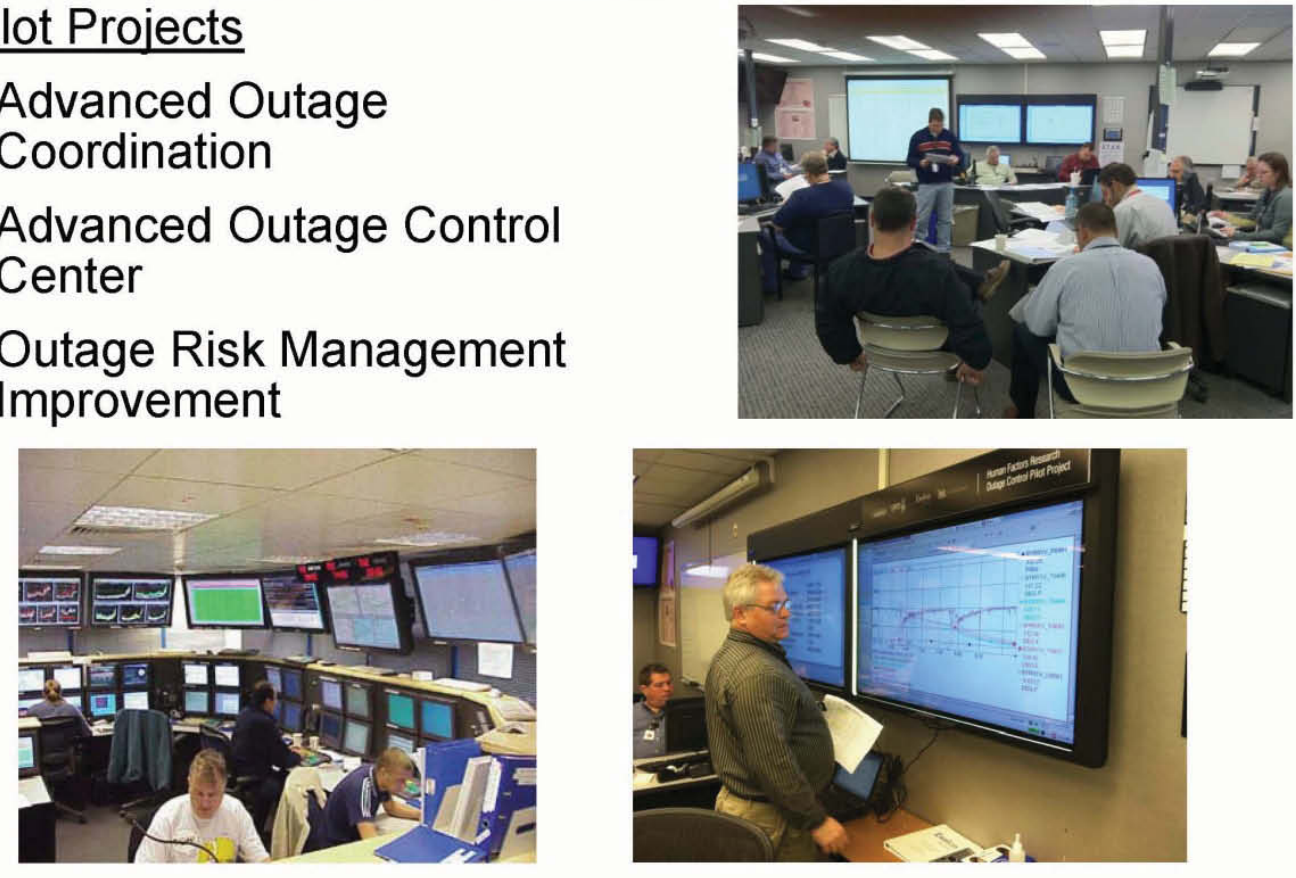


\section{Going Forward.....}

Shift the digital strategy from a systems-based approach to a performance-based approach

Blend the worlds of systems, work processes, and human performance

Leverage the wide spectrum of new technologies and innovations

Transform our business to achieve significant performance improvement 


\section{Appendix E}

\section{ANS UWC Advanced II\&C Working Group}




\section{Appendix E}

\section{ANS UWC Advanced II\&C Working Group}

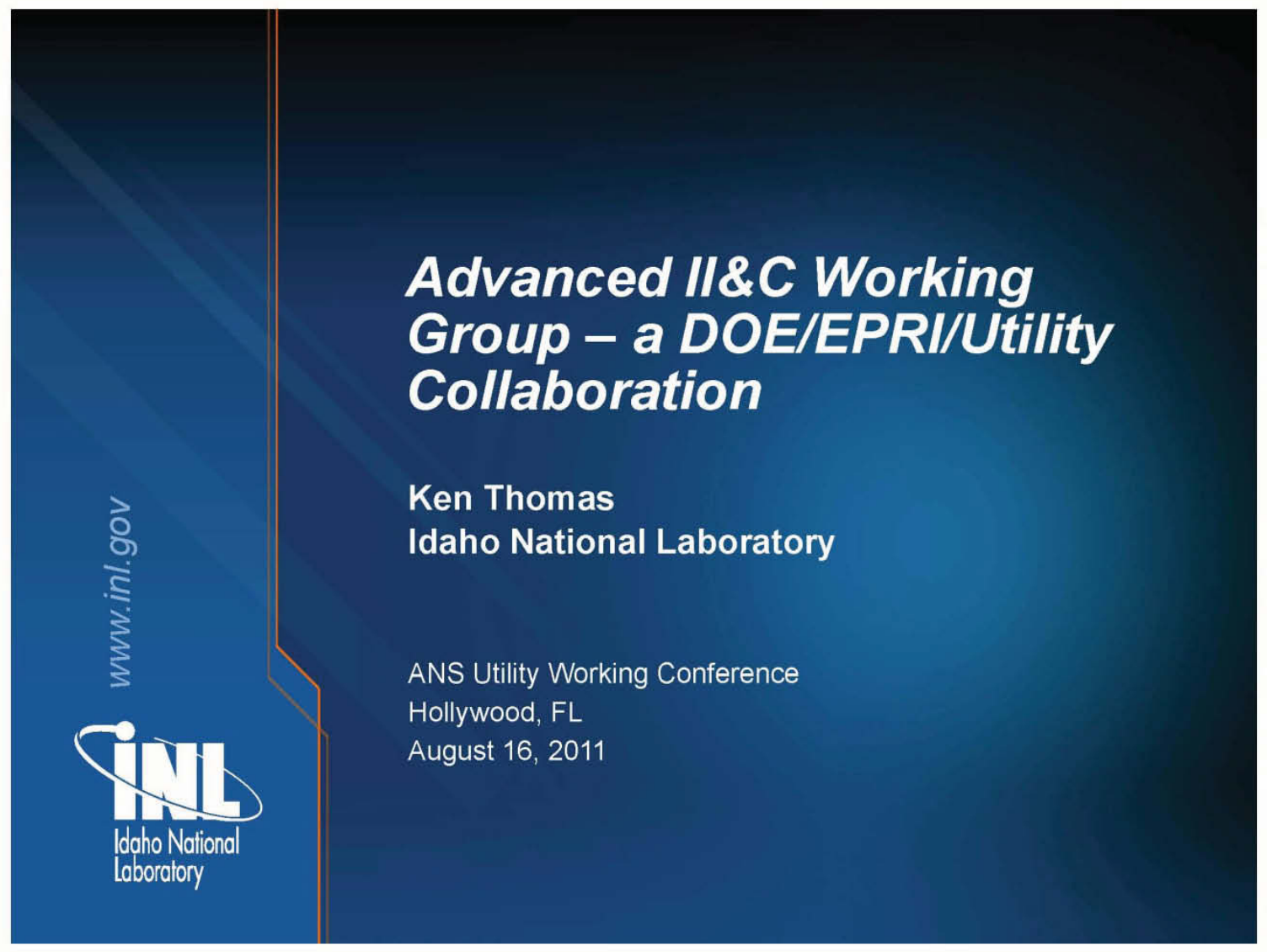




\section{IIdaho National Laboratory}

\section{Advanced II\&C Systems Technologies}

Technologies for and demonstrations of highly integrated control and display technologies that address long-term objectives of nuclear power plant operation, including the following:

- Fleet-wide management of asset information to support integrated operations

- Improved visualization and use of information to support decision-making and actions

- Greater automation of functions and availability of operator support systems to improve efficiencies and reduce errors

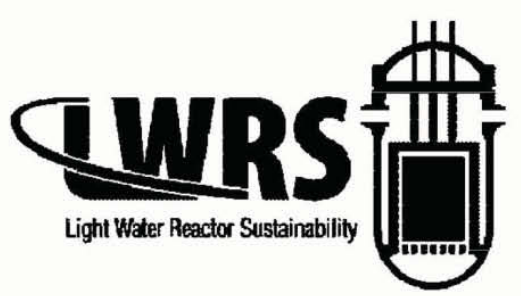




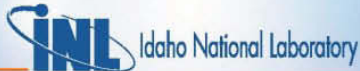

\section{Engaging the Nuclear Power Industry}

- Research and development of near-term beneficial technologies while building the digital work environment of the future

- Integrating plant systems, plant processes, and human performance

- Project definition and control using Cooperative Research and Development Agreements (CRADA)

- In-kind contribution from industry - time, expenses, plant access, plant expertise, reference documents, and other resources (e.g. simulator)

- Industry hosts the technology demonstration and effectiveness assessments

- INL provides research \& associated technologies,

- training \& implementation, and research reports

- INL facilitates industry-wide adoption of new capabilities

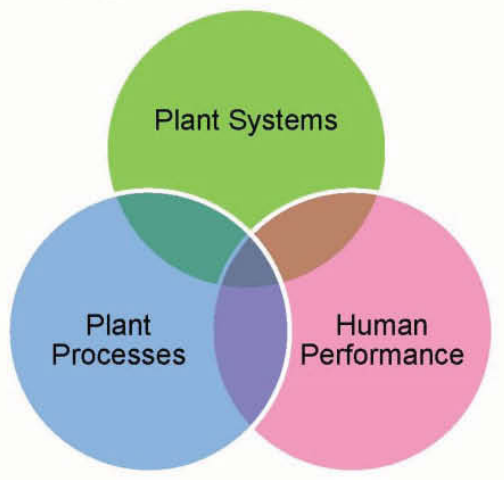




\section{Industry Working Group}

Exelun.

Daps
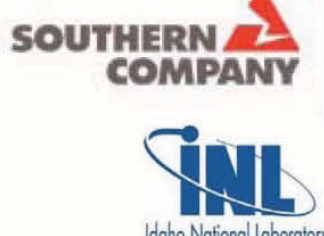

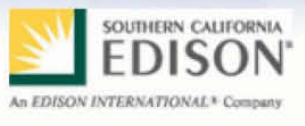

Constellation Energy
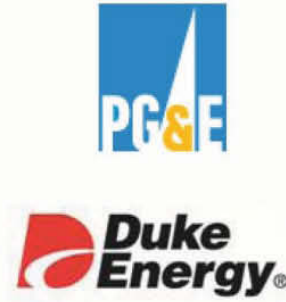

\section{Idaho National Loboratory}

\section{Entergy.}

THE POWER OF PEOPLE.

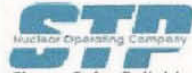

Clean, Safe, Reliable

- Composed of innovation leaders within these companies

- Provides critical input on industry needs and long-term vision of a future integrated digital environment

- Provides opportunities for pilot projects where there is alignment with innovation initiatives within these companies

- Includes close coordination with EPRI, NRC, and Halden Reactor Project 


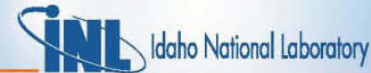

\section{Science Based Approach}

\section{Approach}

- Transformation of plant functions

- Development of enabling technologies

- Demonstration before deployment

Addresses

- Ingrained limiting paradigms

- Technology obsolescence

- Future workforce

- Human error

End-State Vision

- NPP modernization and renewal

- Extended plant life with sustainable operating model

- Enhanced nuclear safety

- Reduced staffing \& O\&M costs
Applied Research Model

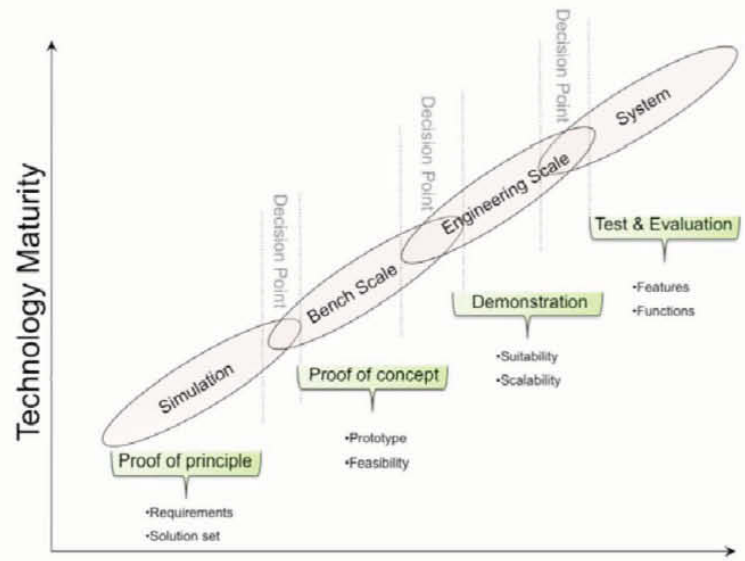

System and Data Qualification Requirements 


\section{TIIdaho National Laboratory}

\section{Reconfigurable Digital Simulation Laboratory}

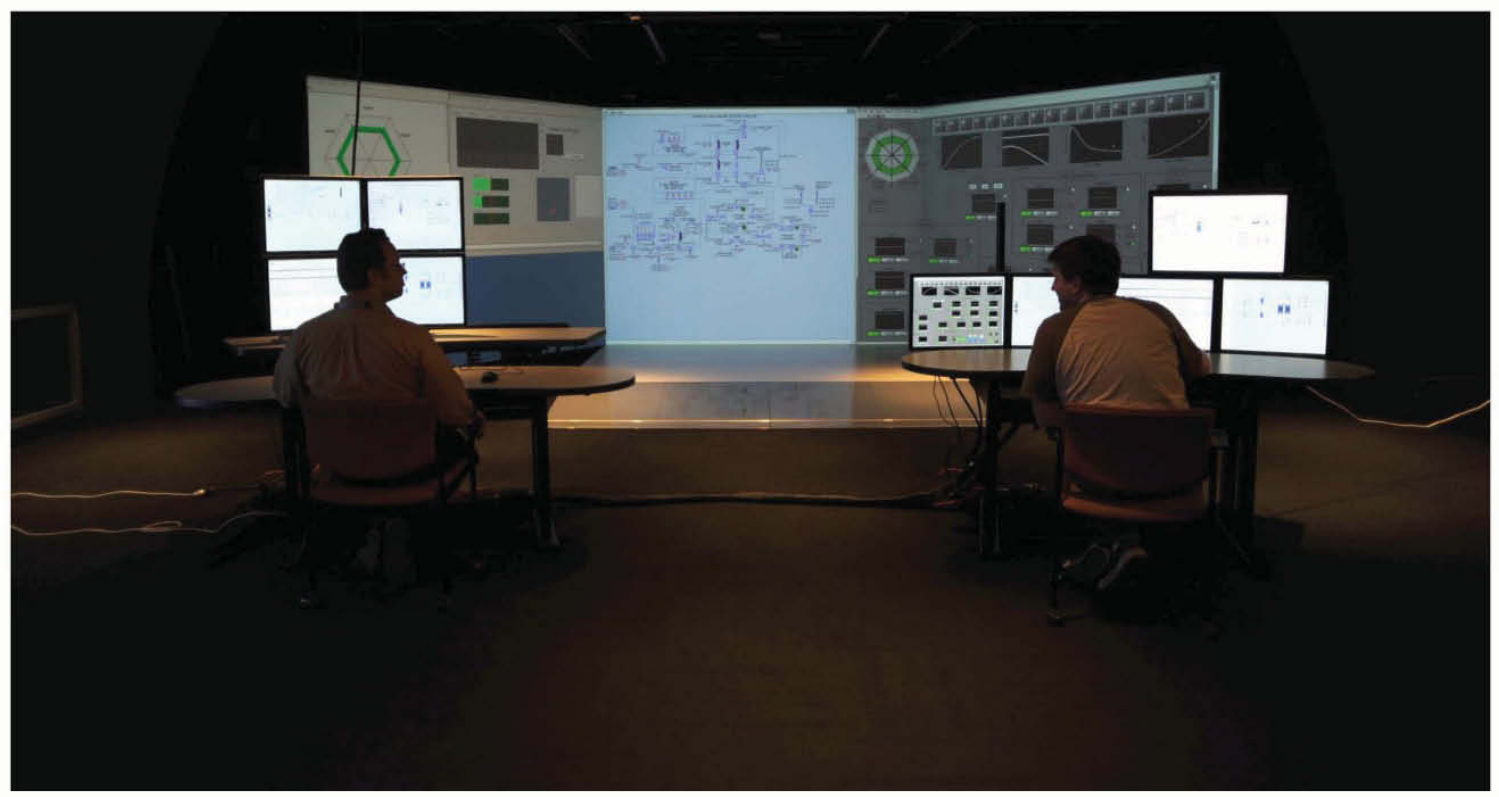


Technology Building Blocks for a Future Digital Environment

- Heads-up information displays

- Wireless streaming of information \& video

- Computer-based procedures

- Component status identification (bar code, RFID)

- Smart Board - large interactive display devices

- Wireless component position indicators

- Alarm management and display technology

- On-Line monitoring systems
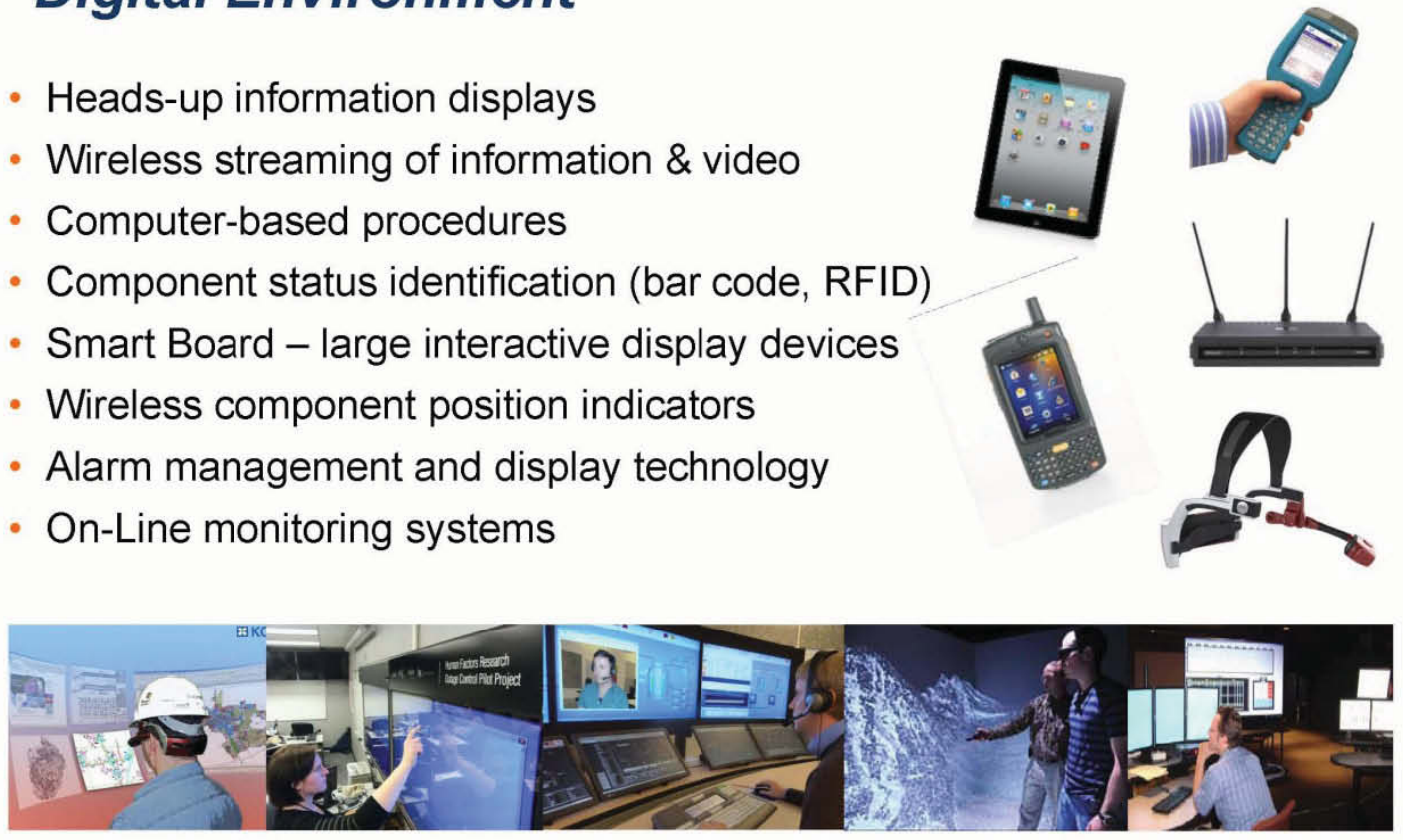


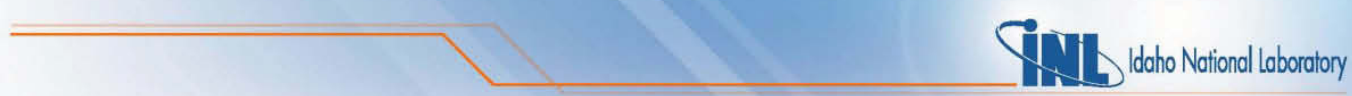

Highly-Integrated Control Room

Pilot Projects

- Incorporating Digital Upgrades in an Analog Control Room

- Advanced Alarm Systems

- Control Room ComputerBased Procedures

- Computerized Operator Support System (COSS)

- Future Concepts of Operation

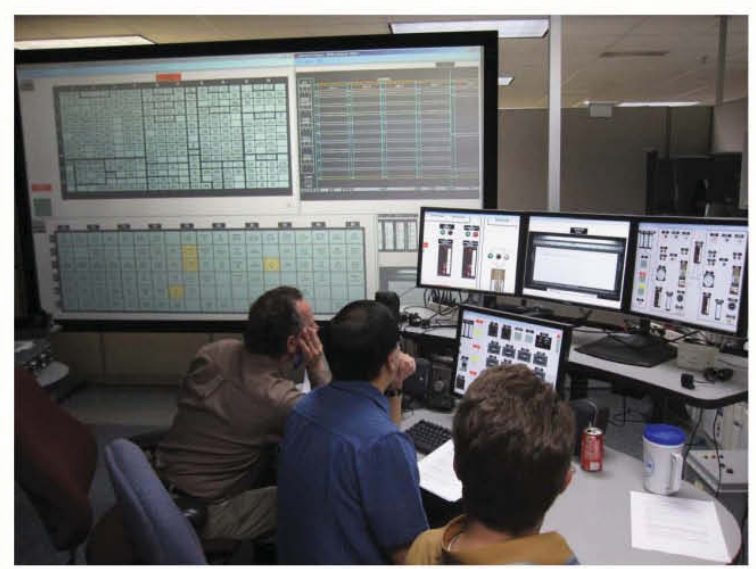




\section{High-Automated Plant}

$\underline{\text { Pilot Projects }}$

- Digital Architecture for a Highly-Automated Plant

- Automating ManuallyPerformed Plant Activities

- Advanced Plant Control Automation

- Advanced Plant Control Algorithms
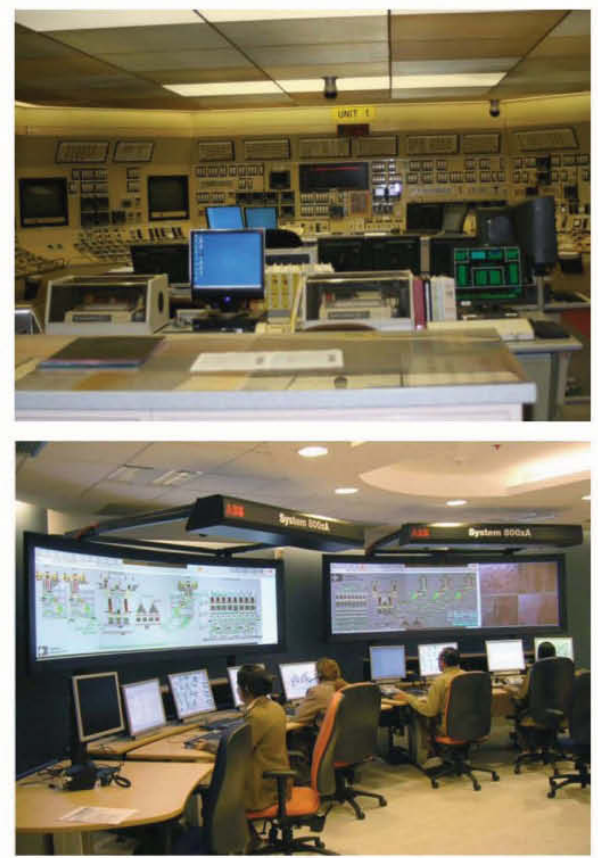


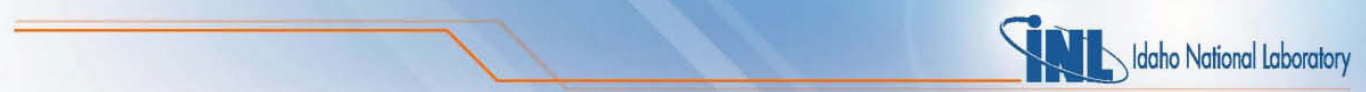

Human Performance Improvement for NPP Field Workers

Pilot Projects

- Mobile Technologies for NPP Field Workers

- Automated Work Packages

- Augmented Reality for NPP Field Workers
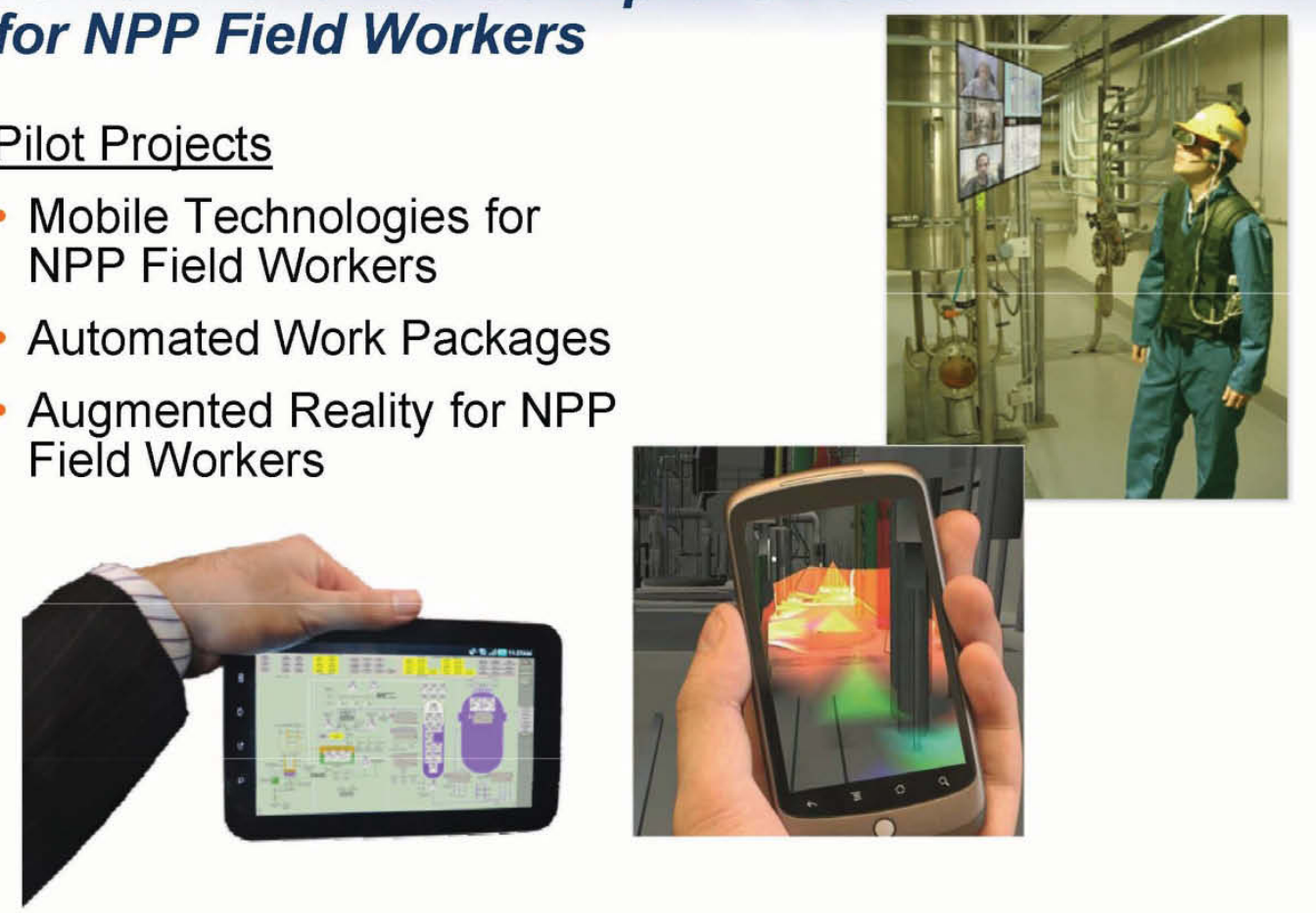


\section{Integrated Operations}

Pilot Projects

- Advanced OLM Facility

- Virtual Plant Support Organization

- Management Decision Support Center
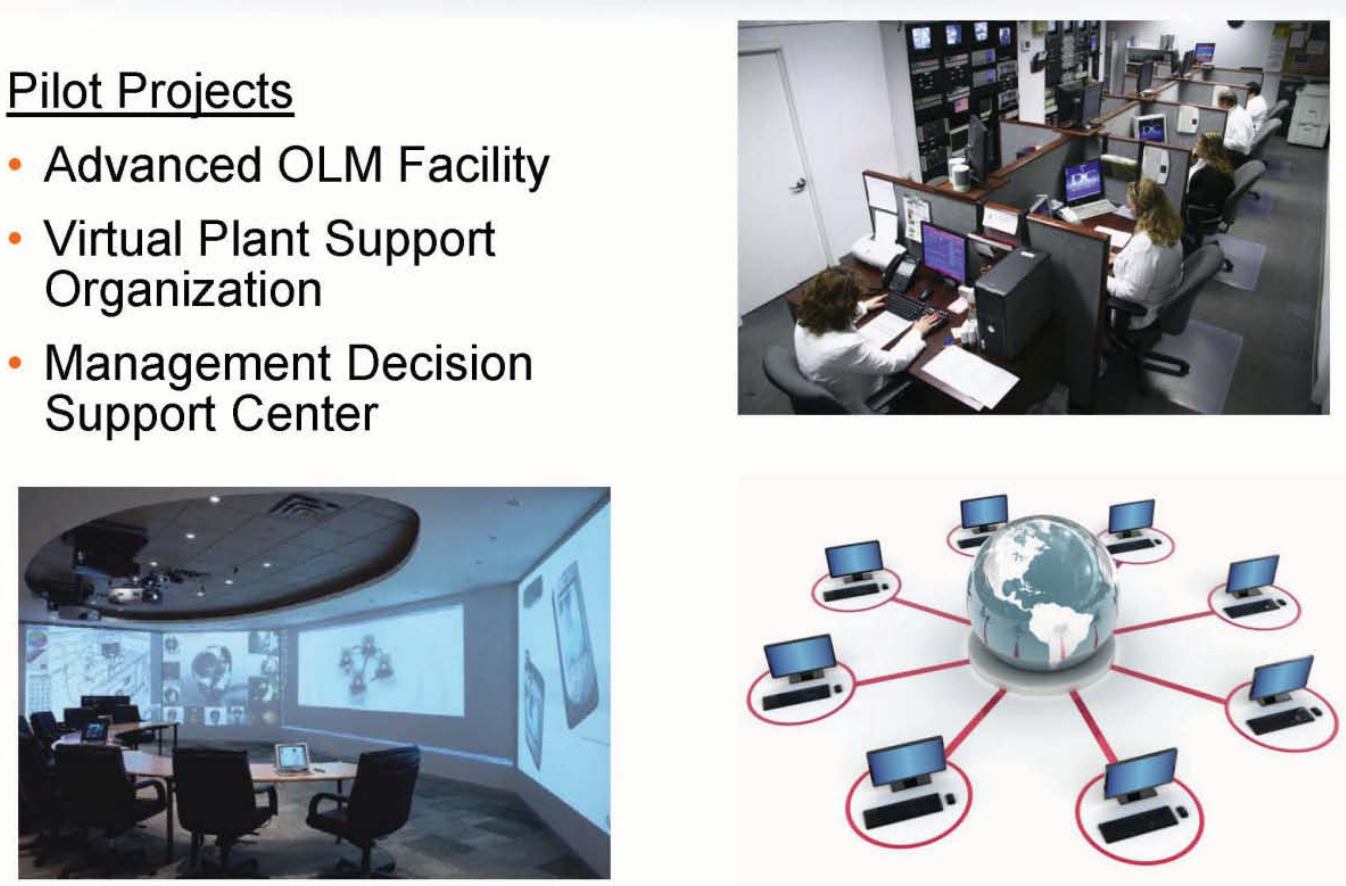


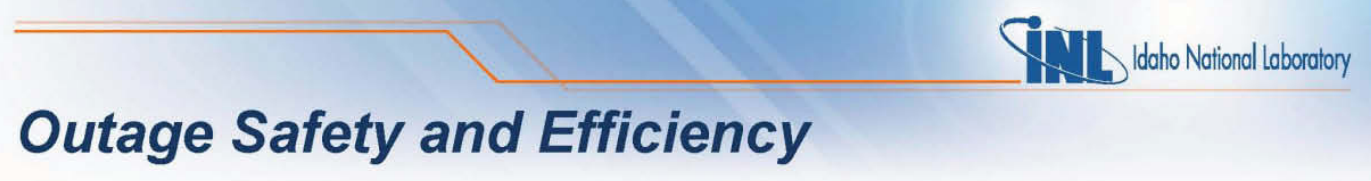

\section{Pilot Projects}

- Advanced Outage Coordination

- Advanced Outage Control Center

- Outage Risk Management Improvement
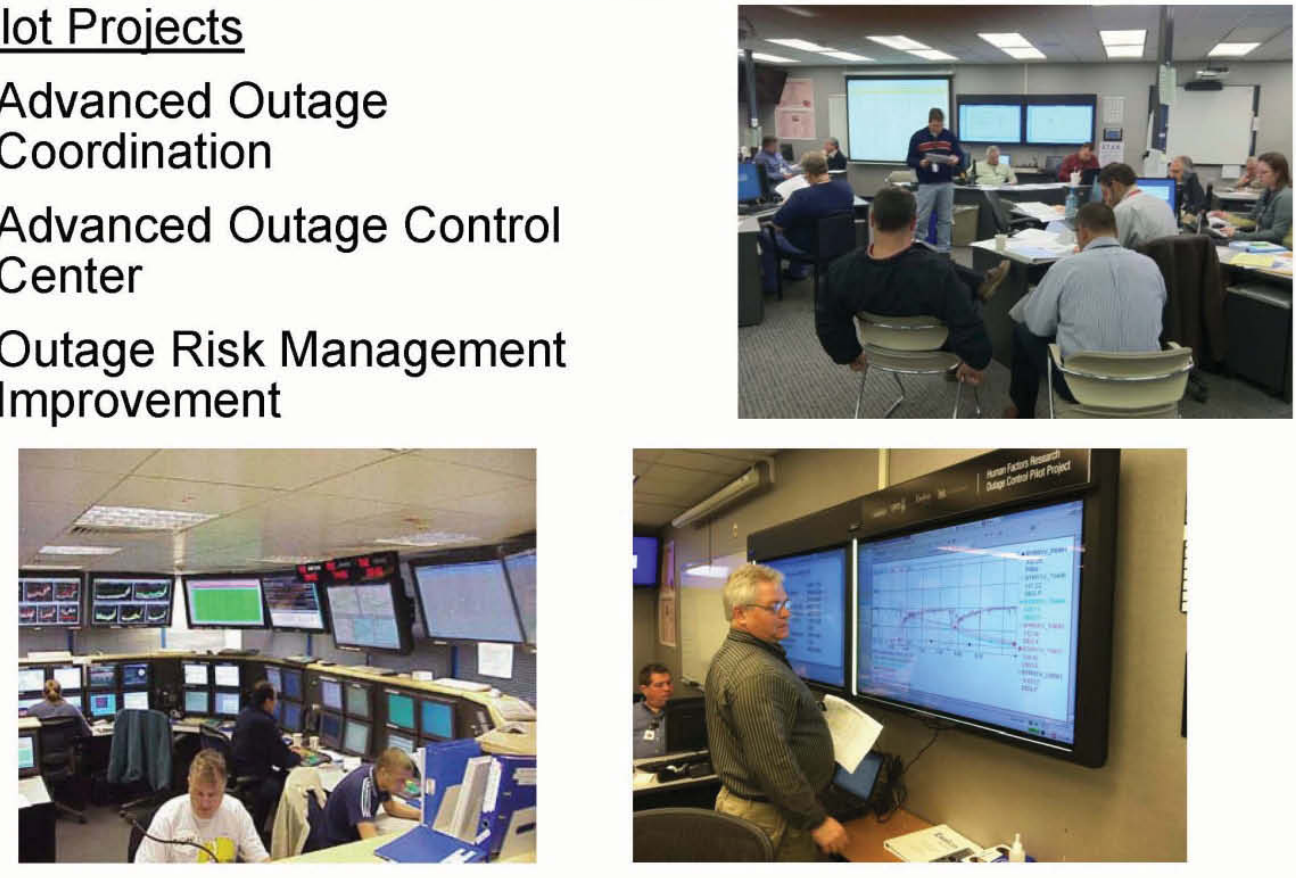


\section{Pilot Project Presentations}

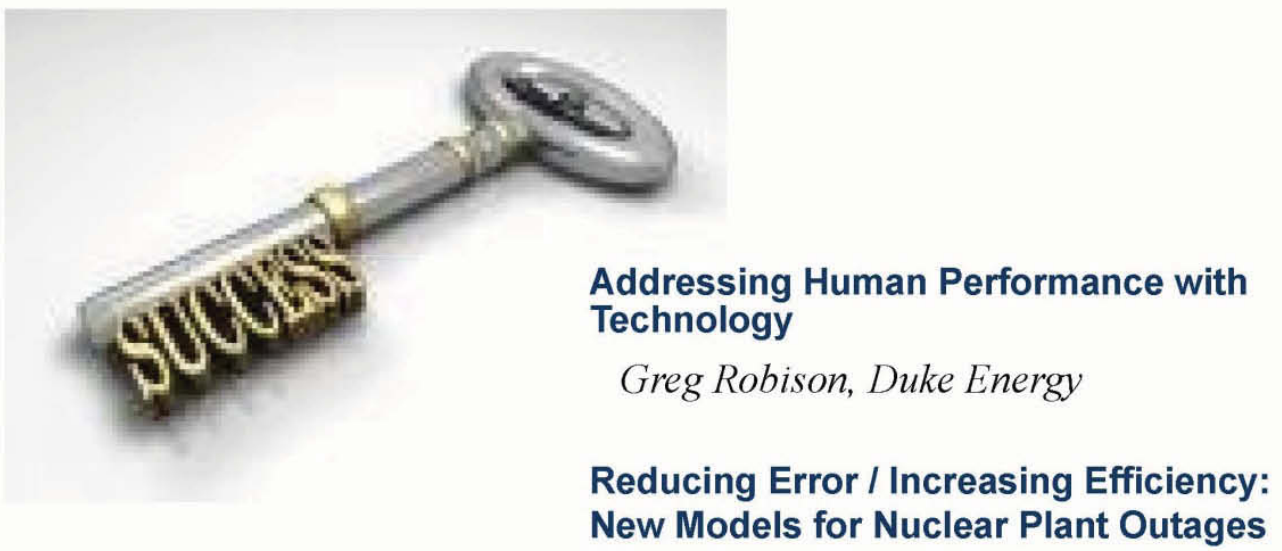

New Models for Nuclear Plant Outages

Keith Moser, Exelon

SONGS Advanced Alarm Systems

Richard Ewing, SCE 